ACCEPTED MANUSCRIPT

\title{
A review of vascular networks for self-healing applications
}

To cite this article before publication: Yasmina Shields et al 2021 Smart Mater. Struct. in press https://doi.org/10.1088/1361-665X/abf41d

\section{Manuscript version: Accepted Manuscript}

Accepted Manuscript is "the version of the article accepted for publication including all changes made as a result of the peer review process, and which may also include the addition to the article by IOP Publishing of a header, an article ID, a cover sheet and/or an 'Accepted

Manuscript' watermark, but excluding any other editing, typesetting or other changes made by IOP Publishing and/or its licensors"

This Accepted Manuscript is $@ 2021$ IOP Publishing Ltd.

During the embargo period (the 12 month period from the publication of the Version of Record of this article), the Accepted Manuscript is fully protected by copyright and cannot be reused or reposted elsewhere.

As the Version of Record of this article is going to be / has been published on a subscription basis, this Accepted Manuscript is available for reuse under a CC BY-NC-ND 3.0 licence after the 12 month embargo period.

After the embargo period, everyone is permitted to use copy and redistribute this article for non-commercial purposes only, provided that they adhere to all the terms of the licence https://creativecommons.org/licences/by-nc-nd/3.0

Although reasonable endeavours have been taken to obtain all necessary permissions from third parties to include their copyrighted content within this article, their full citation and copyright line may not be present in this Accepted Manuscript version. Before using any content from this article, please refer to the Version of Record on IOPscience once published for full citation and copyright details, as permissions will likely be required. All third party content is fully copyright protected, unless specifically stated otherwise in the figure caption in the Version of Record.

View the article online for updates and enhancements. 


\title{
A REVIEW OF VASCULAR NETWORKS FOR SELF-HEALING APPLICATIONS
}

Yasmina Shields ${ }^{1}$, Nele De Belie ${ }^{1}$, Tony Jefferson ${ }^{2}$ and Kim Van Tittelboom ${ }^{1}$

${ }^{1}$ Magnel-Vandepitte Laboratory, Department of Structural Engineering and Building Materials, Faculty of Engineering and Architecture, Ghent University, Technologiepark Zwijnaarde 60, B9052 Ghent, Belgium

${ }^{2}$ Cardiff School of Engineering, Cardiff University, Cardiff, Wales CF24 3AA, United Kingdom

\begin{abstract}
Increasing awareness for sustainability has led to the development of smart self-healing materials, which can extend the service life and improve safety without human intervention. Vascular networks are observed in biological systems, such as leaf venation and blood vascular systems, and provide inspiration for self-healing mechanisms in engineered systems. Embedding a vascular network in a host material has the advantage of addressing varying magnitudes of damage and allowing for an indefinite replenishment of the healing agent, which are current limitations of intrinsic and capsule-based self-healing systems. These networks are demonstrated in polymer and composite materials, with fabrication methods including removal of sacrificial elements, electrospinning, and an array of additive manufacturing (AM) techniques. Advances in AM allow more complex network configurations to be realized that optimize fluid distribution and healing potential. This review intends to provide a comprehensive overview of the current progress and limitations of the design approaches, fabrication methods, healing mechanisms, and relevant applications of embedded vascular networks. Additionally, significant research gaps and future research directions for vascular self-healing materials are described.
\end{abstract}

\section{Contents}

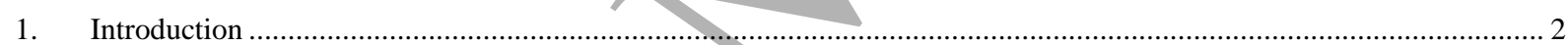

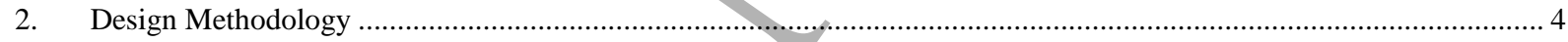

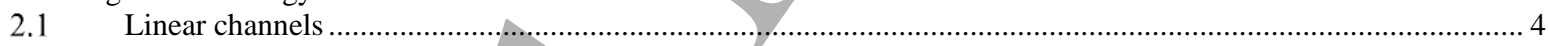

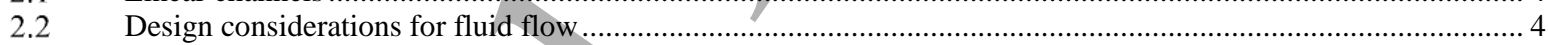

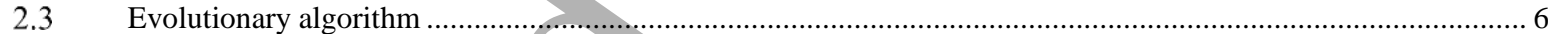

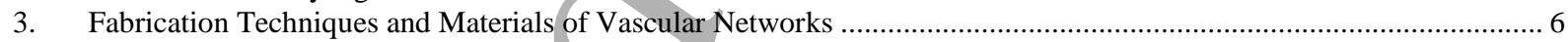

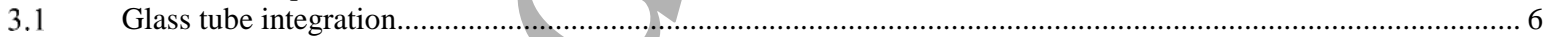

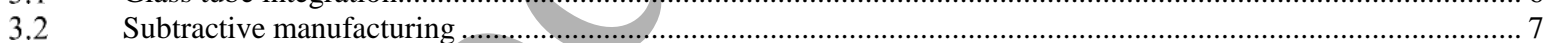

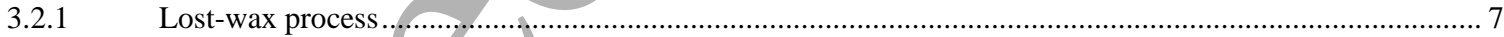

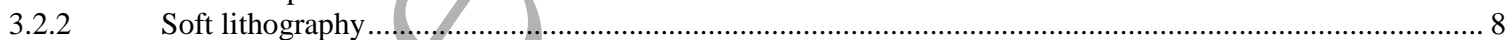

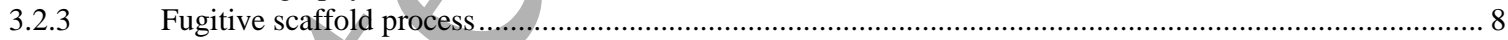

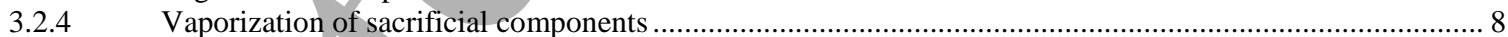

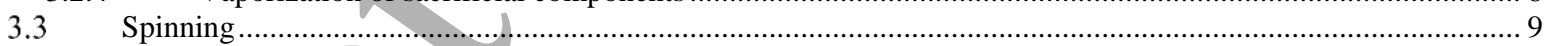

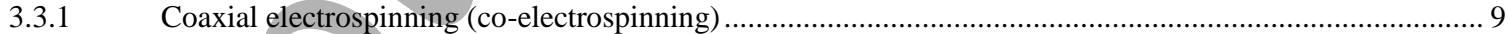

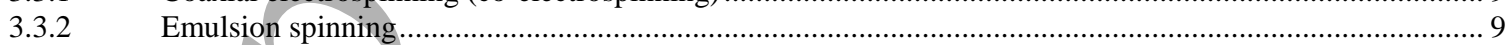

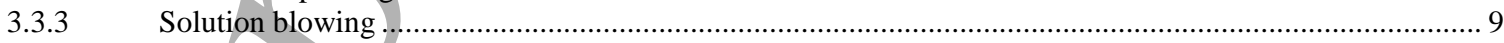

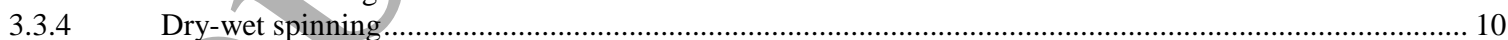

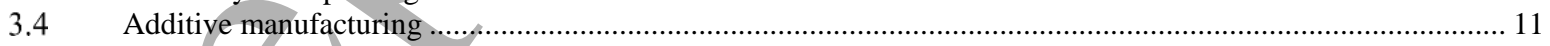

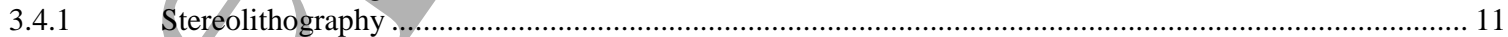

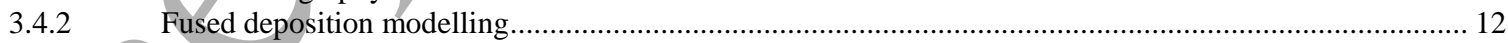

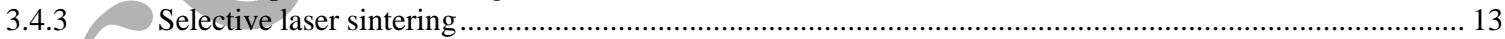

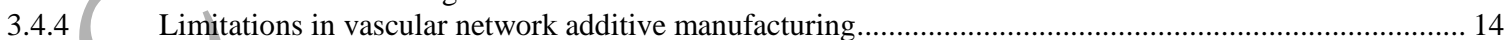

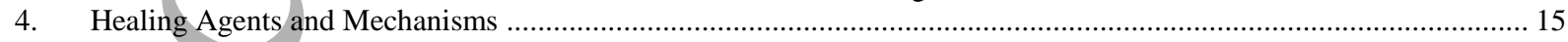

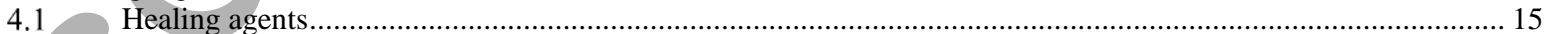

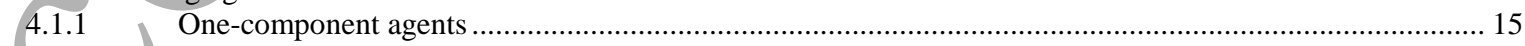

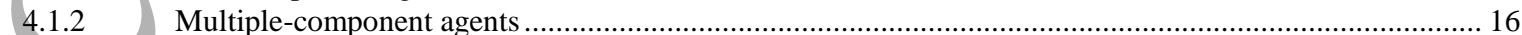

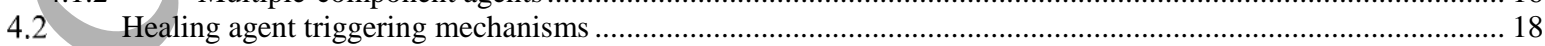

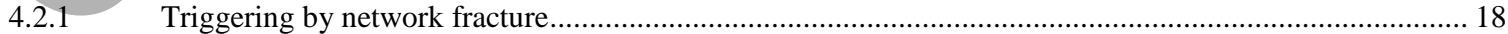

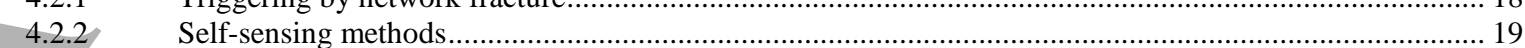

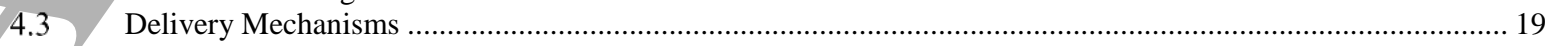




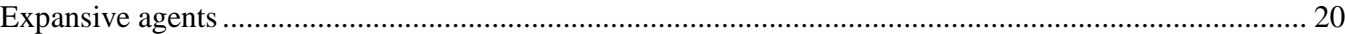

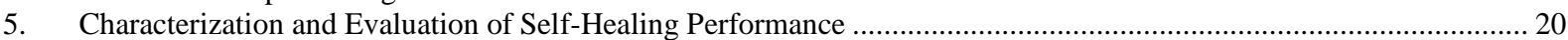

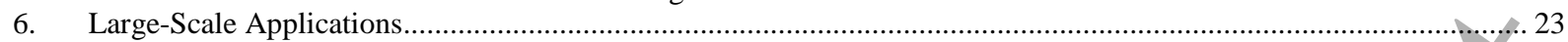

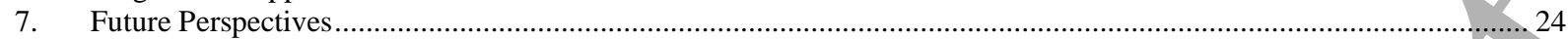

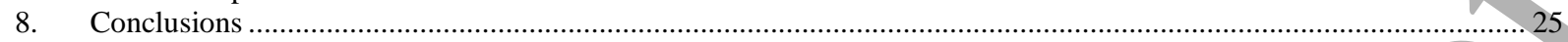

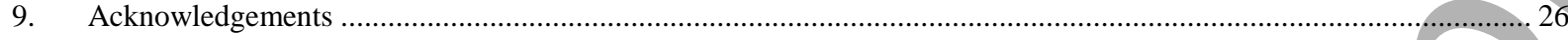

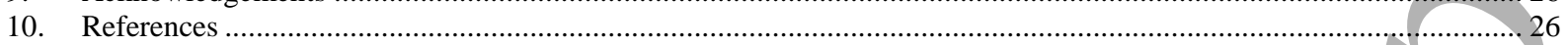

\section{Introduction}

Self-healing materials have the potential to reduce material consumption, cost, and environmental impact on industries such as transportation, telecommunication, àerospace, medical, and construction. Current design philosophies are in certain respects conservative and can lead to oversized structures. High maintenance costs also result from a continued need for non-destructive evaluation, and traditional repair techniques are limited to surface treatments that do not address internal damage.

The effectiveness of self-healing technologies has been demonstrated for polymer, composite, and metallic materials, whose healing mechanisms can be broadly categorized into intrinsic, (micro)capsule based, and vascular systems (Figure 1) [1], [2]. Intrinsic methods rely on latent properties that are triggered by an external stimulus, working via thermally reversible reactions, hydrogen bonding or ionic interactions. Capsule based self-healing materials contain liquid-filled capsules that rupture upon cracking within the material, releasing a liquid healing agent to heal the damage, either by chemical reaction (i.e. polymerization) or by physically filling the crack [3].

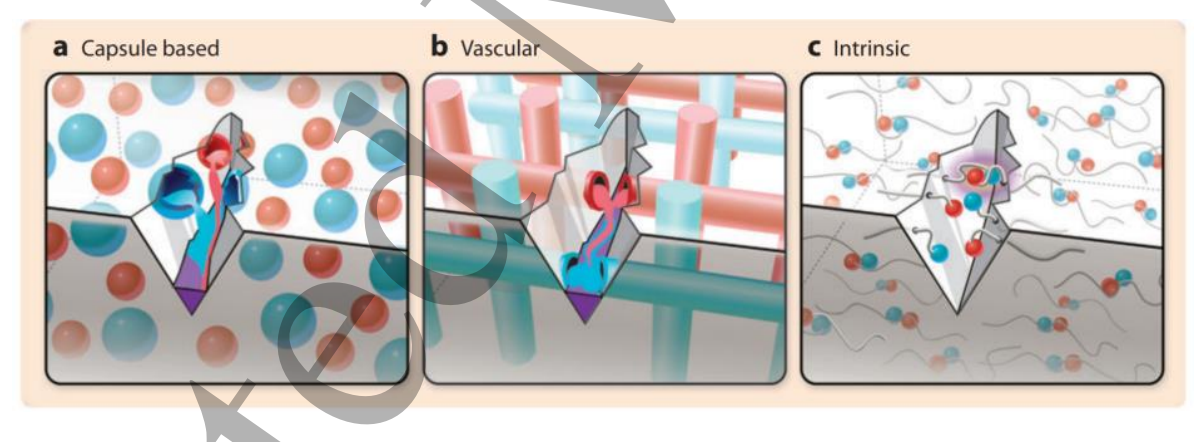

Figure 1. Self-healing approaches include a) capsule based, b) vascular, and c) intrinsic systems [1].

While intrinsic and (micro)capsule-based methods have been proven techniques for selfhealing in a range of materials for small to moderate damage volumes, they are typically limited to one-time use due to healing agent exhaustion, preventing further healing cycles. A vascular network generally has the same healing mechanism as capsule-based systems, but allows for a continuous supply of healing agent to damaged locations within a material, can address different magnitudes of damage, and has the ability to be pressurized, thus further increasing healing agent distribution potential for multiple healing cycles. Hansen et al. [4] found that interconnected (dual) networks significantly outperformed both microcapsule and single tubular networks for self-healing. In their work they defined the healing efficiency, $\eta$, as the ratio of healed fracture load to the original fracture load, and calculated by $\eta=$ 
Figure 2. Comparison of healing efficiencies of microcapsule, single network and interconnected (dual) networks [4].

Self-healing in metals and metal composites has been demonstrated, but is limited due to the additional challenges that exist for healing, as metallic materials require higher temperatures or specialized environments for repair [5]. Highly-cited reviews are referenced herewith for self-healing polymers [6]-[9] and composites [10]-[12], and these materials will be further discussed throughout this review.

Demand for self-healing polymers in lieu of non-renewable petroleum-based polymers has been on the rise due to fossil resource depletion and climbing oil prices [13]. Thermosetting polymers and polymer composites, such as bulk polymers, fiber reinforced polymers (FRPs), and sandwich cores used in structural applications are subjected to mechanical loading and cyclic thermal fatigue which develop microcracks. Carbon fiber reinforced polymer composite laminate materials are commonly used in aircraft manufacturing due to their relatively higher specific strength and stiffness properties, however, they are inherently brittle in nature due to poor out-of-plane properties and are prone to impact damage [14]-[16]. Other industrial applications of woven textile composites include ballistic armor, marine structures and aerospace structural materials. Concrete, a widely used construction material, will inevitably crack. This is due to either loading damage, freeze-thaw action, early-age shrinkage, thermal effects, or a combination of these. Enabling concrete to repair itself can reduce service disruptions to the public, reduce safety risks for repair in difficult locations, and reduce overall maintenance costs. Extending the service life of this material reduces the impact that cement production has on the environment.

One of the first instances of a vascular self-healing system in general was investigated by $\mathrm{C}$. Dry during the 1990s in [17], where embedded glass tubes were used to distribute a healing agent through concrete beams. Engineered materials utilizing vascular networks have since evolved from linear tubular structures to two- or three-dimensional networks with some degree of network design optimization to enhance healing performance. Network fabrication, healing mechanisms, healing agent flow behavior, network material compatibility with various healing agents, and restoration of mechanical properties are already being explored in research in different materials, with potential for further network design optimization for fluid 
flow throughout a material. While this original review draws comparisons of vascular selfhealing methods across various materials, it highlights the collaborative effort needed among researchers working on different material classes, allowing them to learn from one another and further enhance their material-specific vascular self-healing systems.

\section{Design Methodology}

\subsection{Linear channels}

Early proof-of-concept research on vascular networks consisted mainly of linear, tubular structures. Lack of interconnectivity restricts flow access and linear systems have inferior performance for fluid flow compared to two- or three-dimensional networks [18]. The advancement in manufacturing technologies, as described in the following sections, have allowed more complex design configurations to be realized, ranging from random configurations to those that are optimized for fluid flow and self-healing.

\subsection{Design considerations for fluid flow}

Constructal law is a physics principle developed by Adrian Bejan that states "For a finite-size system to persist in time (to live), it must evolve in such a way that it provides easier access to the imposed (global) currents that flow through it" [19], and has provided the basis for optimizing simple configurations and for efficient design of multi-functional flow networks [20], [21].

Bejan et al. [22] configured multiple network geometries as a grid rather than a tree formation to determine which network allowed healing agents within a composite to travel the fastest to any randomly formed crack. Leveraging constructal law, they considered two types of grids, one with consistent channel diameters and regular polygonal loops (square, triangle and hexagonal), and another with grids of two channel sizes. They found that the triangular grids were two times more permeable than the square and hexagonal grids, and optimizing the ratio of the diameters reduced the healing agent delivery time by half. This study was expanded by Wang et al. [23] where they explored flow/access by evaluating multi-scale grids versus trees. They concluded that the tree architecture outperforms the grid, however they found it is better suited for elements where the crack location is already known. A grid design is more effective when there is uncertainty in the crack locations, as the grid spacing is the same as the crack width and thus has a high probability of intercepting damage; however, this methodology will result in a denser network and could weaken the host material.

Having a high vessel coverage increases the chance of a crack intercepting the network and releasing healing agent, however a large volume of voids introduced by the hollow network can impact the mechanical properties of the material, requiring a minimization of the void volume fraction imposed by the network [24]-[26]. Additionally, having a relatively dense network configuration can induce localized strain in the host material and degrade its mechanical properties. Hamilton et al. [27] found that reducing the vascular channel spacing in a polymer epoxy matrix would increase the amount of strain near the channels.

Self-cooling vascular systems have altered design configurations for effective fluid flow and cooling performance, and can be applied to self-healing vasculature [28]-[30]. Yenigun et al. 


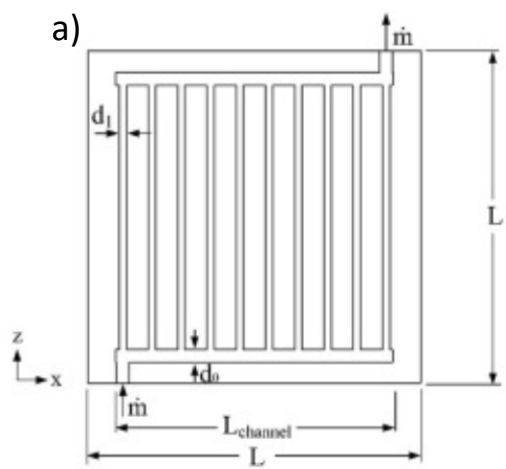

b)

[31] explored the effect of the volume fraction and number of channels for self-cooling aluminum plates by comparing parallel channels, tree networks, and a hybrid parallel-tree network (Figure 3). Tree networks were found to provide less flow resistance for the same volume fraction as a parallel system, and the hybrid system reported the highest volume flow rate.

Figure 3. a) Parallel, (b) tree, and (c) hybrid parallel-tree network design for a self-cooling aluminum [31].

Internal vessel diameters and internal wall roughness can affect the fluid flow efficiency of a vascular network [32], with larger size vessels being better suited to service large-scale damage [33], [34]. Network redundancy is an additional design parameter for vascularization; vascular networks are subjected to blockage, reducing their performance and functionality [35]. Pety et al. [36] presented an optimization scheme of incorporating redundant networks in a self-cooling poly(dimethylsiloxane) (PDMS) panel so that sufficient cooling capacity could be provided, even if the network was partially blocked.

Biomimetics looks to nature as an inspiration for network design, which can be modelled using Murray's Law and implemented in synthetic systems. Murray's law describes the relationship between parent and daughter branches of a network that minimizes power required for fluid transport. In his investigation of vascular blood vessels, Murray determined the cube of a parent vessel's radius, $r_{p}$, is equal to the sum of the cubes of the daughter vessels' radii, $\mathrm{r}_{d}$; Equation 1 describes the case of a vessel with two daughter branches. The derivation for Murray's law is presented in [37].

$$
r_{p}^{3}=r_{d 1}^{3}+r_{d 2}^{3}
$$

(Equation 1)

Biomimetic network designs have been implemented for self-healing functionalities in polymer composites [3], [38], [39], bulk polymeric materials [40], [41], core structures of composite sandwich panels [42], [43] and in cementitious materials [18]. These studies were able to demonstrate repeated self-healing in the matrix material and little degradation of mechanical performance. Embedding biomimetic vasculature has proved to be a challenge for fiber reinforced polymer laminates, as different channel orientations can disrupt the fiber architecture and reduce its strength and modulus, as well as increase crack density [44], [45]. Studies on carbon-epoxy laminate materials have shown that channels oriented transverse to the loading axis reduced tensile and compressive properties more than channels oriented longitudinally [46], [47]. 


\subsection{Evolutionary algorithm}

Evolutionary algorithms are biologically-inspired methods that show promise to the development of optimized networks due to their applicability to different fields and ability to consider a large amount of parameters while solving for multiple interrelated variables [48][50]. This computation method draws inspiration from Darwin's theory of evolution, where natural selection modifies subsequent generations for suitability to the environment. A population is first randomly generated, and the evolutionary algorithm searches for better candidates by applying a fitness function that assesses its suitability over a loop of a predetermined number of iterations, or generations. The parent population of the next generation are determined by applying the genetic operators of selection, crossover and mutation. The selection operation is analogous to "survival of the fittest," where the individuals that are best fit remain in the pool for subsequent reproduction. Crossover is the mixing of genetic information of two or more characteristics (or chromosomes), and mutation is a slight modification of the individual's characteristics to generate diversity and to prevent local optimums [51].

Genetic algorithms, the most popular of the evolutionary algorithms, have been successfully applied to flow network optimizations [50], [52], [53]. Aragon et al. [48] used a genetic algorithm to design microvascular networks for polymeric self-healing materials, taking into account network redundancy, vascular geometry, and diameters of the channels to develop a network that uniformly distributes a healing agent.

\section{Fabrication Techniques and Materials of Vascular Networks}

Replication of vascular networks found in nature poses a fabrication challenge due to their complex architecture. The following sections detail the methods and materials that have been used to-date to fabricate vascular networks towards self-healing purposes, in order of increasing complexity, culminating in the final section of advanced additive manufacturing (AM) techniques.

\subsection{Glass tube integration}

Early self-healing vascular studies integrated glass fibers, or tubes, within a matrix for polymeric-composites [46], [54]-[56] and concrete materials [57]-[61]. A hybrid system composed of glass networks and shape memory alloys (SMA) was investigated as well in [62], [63], where SMA wires were used to restrict the crack widths for more effective healing. Glass is chemically inert with common healing agents and is readily available via industrial production. Due to their brittle behavior, glass tubes break upon crack formation, thereby releasing the contained healing agent. While these have proven to be effective at short term healing, glass can induce alkali-silica reactions within concrete and may not survive in the long-term due to the material's aggressive chemical environment [12], prompting further studies to determine suitable network material alternatives for vascular networks in concrete applications [64], [65]. Additionally, it can be too fragile to survive some manufacturing processes. While hollow glass fibers or tubes are ideal for crack formation triggering mechanisms and compatible with many material matrices, they are limited to onedimensional, linear vascular configurations. 


\subsection{Subtractive manufacturing}

\subsubsection{Lost-wax process}

The formation of hollow channels within fiber-reinforced composite laminates and ceramic materials through a "lost-wax process" has been used as a viable network manufacturing technique, where a pre-formed sacrificial material is embedded in the host material and subsequently removed to yield a network of hollow channels.

Low melting temperature (LMT) wires were employed by Trask et al. [66] to fabricate a hollow network in a composite laminate, studying the effect of different network orientations with respect to the fiber direction, including $0^{\circ}, 45^{\circ}$ and $90^{\circ}$. After curing, the LMT was heated in a vacuum, leaving hollow channels within the host. In networks aligned with fibers, some fiber waviness was observed, and through impact testing, transversely-oriented networks were shown to increase the damage area and reduce impact strength. Orienting network tubes transverse to the fiber laminate direction would reduce voids between the fibers, leading to controlled crack behavior (Figure 4). In contrast to low temperature wires, high melting temperature steel wires manually coated in a thin polytetrafluoroethylene (PTFE) layer have been used to create hollow networks in laminates [45], [67], which eases removal of the wires from the host material. This method has been successfully employed for a self-healing fiber reinforced composite [45], and yielded a 96\% recovery in post-impact compressive strength.

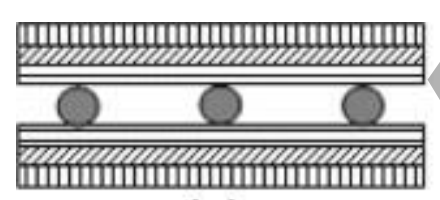

(a)

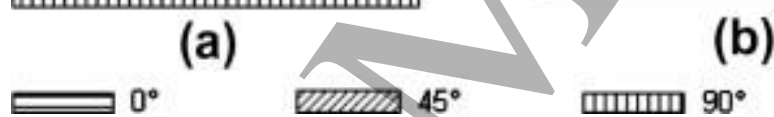

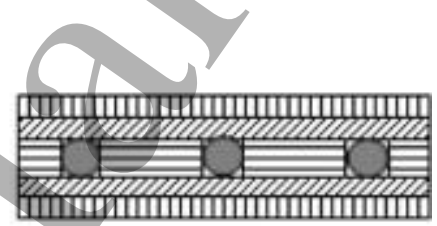

(b)

Figure 4. Network tubes oriented transverse to the fibers (a) in the midplane (with voids in between wires) and (b) within a cut recess [34].

Heat shrink, or polyurethane tubing was investigated to form hollow tunnels in concrete specimens in [68]. Polyolefin was used as the heat shrink material, having a shrinkage ratio of 2:1 at $80^{\circ}$ and thus allowing for ease of removal following concrete placement, curing, and demolding. To remove, the polyolefin tubing is flushed with hot water at a temperature over $80^{\circ}$, shrinking it to half of its original diameter.

3D printed polyvinyl alcohol (PVA) structures embedded in cement pastes and subsequently removed after curing was investigated by Li et al. [69]. PVA is used mainly in medical applications, such as soft contact lenses and eye drops, due to its low toxicity, biocompatibility, and high water solubility [70], making it ideal for handling purposes and as a sacrificial material. A complex, double twisted channel was designed and 3D printed, and dissolved in water following cement paste curing. However, the water to cement ratio in the cement paste needed to be adjusted in order to avoid early age cracking of the cementitious matrix due to volume expansion of the PVA. 


\subsubsection{Soft lithography}

Soft lithography works by replicating existing patterns and has been used to construct microchannel arrays for fluidic devices [71], [72], as well as to fabricate microvascular selfhealing materials. Golden et al. [73] fabricated sacrificial gelatin meshes in a hydrogel with channel diameters on the order of $\sim 6-50 \mu \mathrm{m}$. Cavities were first formed on a glass substrate in a vascular pattern, creating a "negative," in which the gelatin was filled and left to form a solid structure on the substrate, as shown in Figure 5. These meshes were integrated inside a hydrogel, and then heated to $37^{\circ} \mathrm{C}$ which would melt the gelatin while leaving the hydrogel intact as it has a lower melting point. The channels were then flushed with either saline or $1 \%$ bovine serum albumin (BSA) through their openings to remove the liquid gelatin. This technique has been used by Bellan et al. [74] to fabricate primary vessels in combination with melt-spinning techniques to form secondary, small diameter vessels, as well as by He et al. [75] to replicate microvascular networks from a plant leaf for use in an engineered tissue design. This process is however limited to producing planar networks and requires additional post processing steps to stack layers together to create a multi-dimensional network.

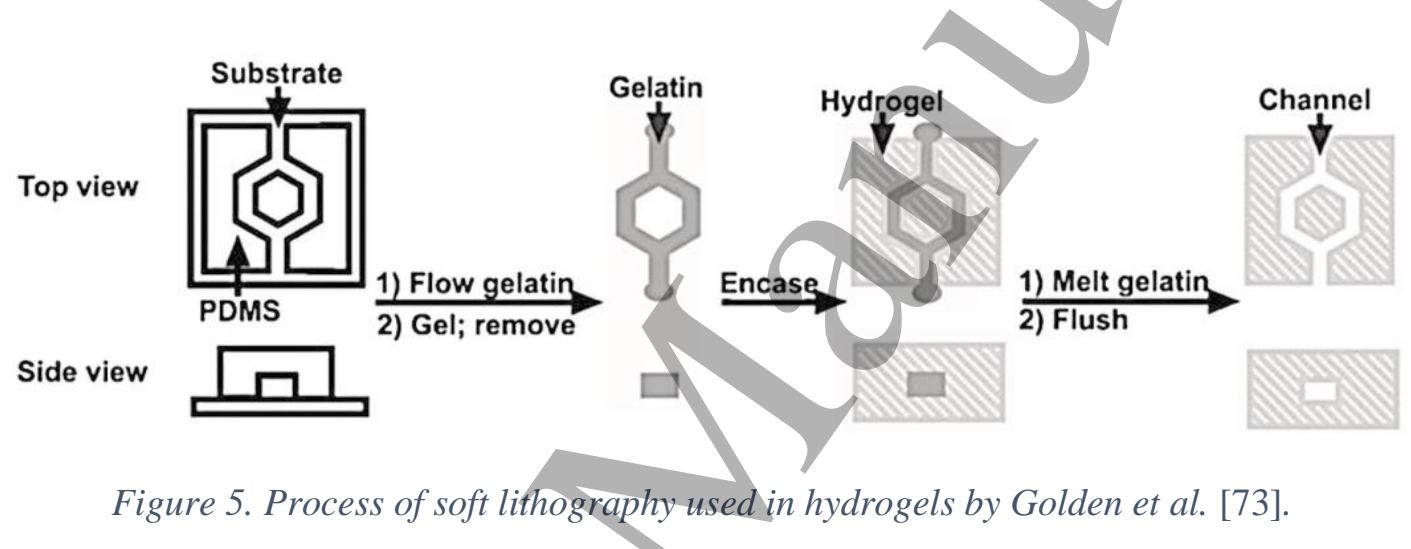

\subsubsection{Fugitive scaffold process}

Three-dimensional (3D) microvascular networks have been designed and realized via directwrite assembly (DWA) fabrication [71], [76], [77], and implemented to repair cracks in an epoxy coating [40]. DWA deposits fugitive ink layer by layer to create a scaffold, with nozzle diameters ranging between approximately $200 \mu \mathrm{m}$ for colloidal inks to $250 \mathrm{~nm}$ for sol-gel inks, with printing speeds between $1-10 \mathrm{~mm} / \mathrm{s}$ [78]. Hansen et al. [79] used DWA to fabricate ternary interpenetrating networks within an epoxy matrix with a brittle coating, where two of the networks were filled with an epoxy resin and amine hardener, respectively, with the third network interlocking them.

\subsubsection{Vaporization of sacrificial components}

3D vascular networks fabricated via DWA of fugitive scaffolds are limited to lowtemperature curing polymers and small-scale elements, and are unsuitable for composite manufacturing as these structures are too delicate to survive the fabrication process. An alternative method to creating compatible networks in composites is the vaporization of sacrificial components (VaSC) [80]. This technique seamlessly integrates a network into the composite volume and can be removed by the VaSC process to form hollow networks capable of circulating functional fluids. Polylactic acid (PLA) fibers are mechanically woven into 3D 
woven glass preforms, ensuring position, length and diameter of the fibers meet the desired design criteria. Connections in the networks are created by either overlapping two perpendicular fibers, where direct contact is maintained by tension in the fibers, and by using trifluoroethanol (TFE) solvent to partially dissolve the PLA to weld fibers together. The pore space between the fibers is filled with a low-viscosity epoxy and cured. After curing, the fiber is removed by heating the sample above $200^{\circ} \mathrm{C}$, which vaporizes the PLA to yield hollow networks.

This method has been expanded successfully for self-healing applications, where sacrificial $3 \mathrm{D}$ vascular networks were introduced in polymeric composites [81], [82]. This method has the advantage that as thermal depolymerization occurs simultaneously throughout the sacrificial material, a network can be rapidly produced. Depolymerization yields a gaseous byproduct which allows for full removal of the sacrificial material, and its depolymerization temperature can be reduced below the decomposition temperature of the surrounding substrate by doping PLA with a tin catalyst [83].

\subsection{Spinning}

\subsubsection{Coaxial electrospinning (co-electrospinning)}

Co-electrospinning has been used to create core-shell networks in polymers and ceramics, producing networks with diameters ranging between $10 \mathrm{~nm}$ and $10 \mu \mathrm{m}$ as well as allowing the fabrication of long-length fibers of several meters [84]-[90]. Fibers are created by applying a high voltage to a metallic nozzle fluid jet that deposits droplets. As charge builds up on the droplet, the surface is stretched to form a Gilbert-Taylor cone. The electric field pulls the fluid toward the grounded electrode surface where it is collected, resulting in solid fibers collected at the surface. To fabricate a hollow self-healing fiber, an inner layer of healing agent and outer layer of network material are coaxially spun, providing that the two liquids are immiscible [91]-[93]. Carbon nanotubes have been fabricated by electrospinning [94] and have potential to store and release a healing agent upon rupture, with some capability to heal itself or form adatom superstructures when damage occurs on their walls [95], [96].

\subsubsection{Emulsion spinning}

Core-shell fibers can also be manufactured via emulsion spinning, where an emulsion of two polymer solutions are electrospun through a single-exit nozzle, as opposed to using separate solutions with a coaxial needle, facilitating the control of the jetted solution compared to controlling a two-solution jet. This was first developed by Bazilevsky et al. [97], where they used blends of poly(methyl methacrylate) (PMMA)/polyacrylonitrile (PAN) solutions in dimethylformamide (DMF). Precipitated PMMA solution droplets became trapped at the base of the Taylor cone delivering the PAN solution from its tip, and demonstrated that the outer shell flow had the durability to stretch the inner droplet into the Taylor cone, thereby forming a core-shell jet. This study was later expanded for self-healing nanofiber coatings for anticorrosive protection [98] and in a self-healing polymer application [94].

\subsubsection{Solution blowing}

Solution blowing is an alternative to the electrospinning method, where compressed air is used to produce nanofiber networks rather than requiring a high-voltage electric field, making 
it a safer manufacturing method (Figure 6) [99]-[101]. Lee et al. [101] found that solution blowing allows core-shell fibers to be produced more efficiently than electrospinning, with a core-to-shell mass ratio 33 times larger (75.62\% compared to $2.29 \%$ ), as well as double the total mass production rate.
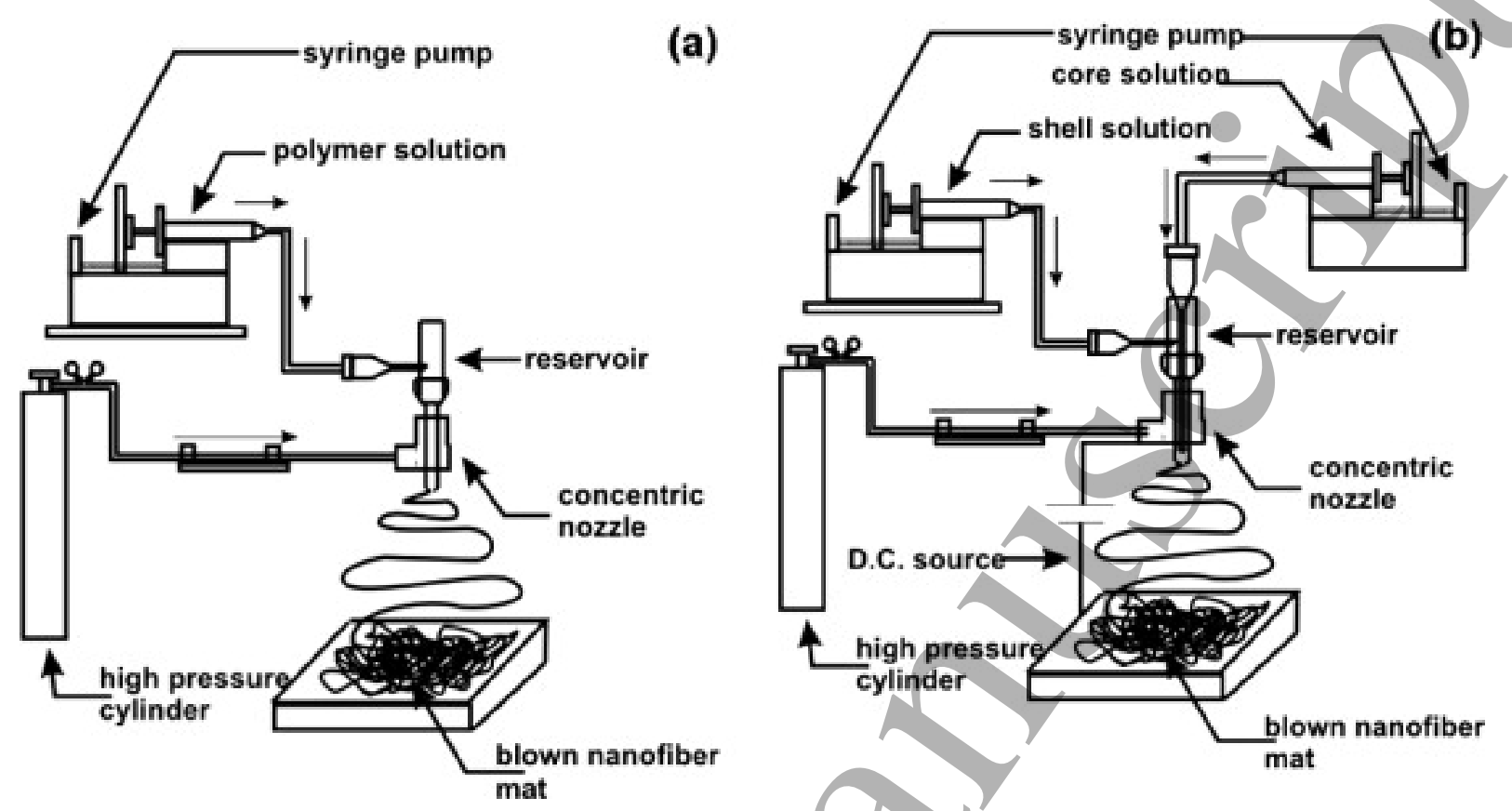

Figure 6. Schematic of the setup for solution blowing of monolithic nanofibers (a) and for the electrically-assisted co-blowing of core-shell nanofibers (b) [99].

\subsubsection{Dry-wet spinning}

Preliminary studies implementing spun networks were conducted by Su et al. [102], [103], where they fabricated poly (vinylidene fluoride) (PVDF) fibers for self-healing bituminous pavement, specifically using a dry-wet spinning technology. PVDF powder is first dried to completely remove moisture and mixed with a solvent of dimethylacetamide (DMAc). The solution is poured into a spinning pot at a temperature of $60^{\circ} \mathrm{C}$. Nitrogen gas $\left(\mathrm{N}_{2}\right)$ was administered at high pressure of $0.15 \mathrm{MPa}$ to extrude the solution from the spinneret to form the shell of the fiber, while the core fluid flows through the central hole of the spinneret and serves as a support. To prevent the core material from leaking from the ends of the fibers, the ends are sealed with a heat sealer. PVDF fibers are hydrophobic, have high mechanical strength and have superior thermal properties due to the presence of fluorine, and can withstand the high asphalt mixing temperatures of $140-180^{\circ} \mathrm{C}$ as its decomposition temperature is approximately $450^{\circ} \mathrm{C}$ [104]. Su [105] developed a novel self-healing porous microfiber containing oily rejuvenator, where the rejuvenator would permeate through the pores of the fiber either through the lipophilicity of the PVDF fibers or via the gradient difference between the rejuvenator and the aged bitumen.

Table 1 summarizes the previously mentioned fabrication methods. 
Table 1. Fabrication techniques used to construct vasculature.

\begin{tabular}{|c|c|c|c|c|c|c|}
\hline $\begin{array}{l}\text { General } \\
\text { Method }\end{array}$ & Fabrication Technique & $\begin{array}{c}\text { Host Material } \\
\text { Application }\end{array}$ & Network Materials & Advantages & Disadvantages & Ref. \\
\hline $\begin{array}{l}\text { Traditional } \\
\text { fabrication }\end{array}$ & Glass tube integration & $\begin{array}{l}\text { Polymeric } \\
\text { composites, } \\
\text { concrete }\end{array}$ & Glass & $\begin{array}{l}\text { Glass is } \\
\text { chemically } \\
\text { inert and } \\
\text { generally will } \\
\text { not react with } \\
\text { a healing } \\
\text { agent }\end{array}$ & $\begin{array}{l}\text {-Limited to one } \\
\text { dimensional } \\
\text { channels } \\
\text {-Often too } \\
\text { fragile to survive } \\
\text { manufacturing } \\
\text { process of the } \\
\text { host material }\end{array}$ & $\begin{array}{l}{[17],} \\
{[106],} \\
{[107]}\end{array}$ \\
\hline $\begin{array}{l}\text { Subtractive } \\
\text { manufacturing }\end{array}$ & $\begin{array}{l}\text {-Lost-wax process } \\
\text {-Soft lithography } \\
\text {-Fugitive scaffold } \\
\text { process } \\
\text {-Vaporization of } \\
\text { sacrificial components }\end{array}$ & $\begin{array}{l}\text { Fiber-reinforced } \\
\text { composite } \\
\text { laminates, } \\
\text { ceramic } \\
\text { materials, } \\
\text { concrete, } \\
\text { hydrogels }\end{array}$ & $\begin{array}{l}\text { Low or high melting } \\
\text { wires, polylactic acid } \\
\text { (PLA), polyolefin, } \\
\text { polyvinyl alcohol (PVA), } \\
\text { gelatin }\end{array}$ & $\begin{array}{l}\text { Can closely } \\
\text { replicate } \\
\text { existing } \\
\text { biological } \\
\text { vessel } \\
\text { natterns }\end{array}$ & $\begin{array}{l}\text { Can result in } \\
\text { reduced } \\
\text { mechanical } \\
\text { properties of the } \\
\text { host material }\end{array}$ & $\begin{array}{l}{[44],[45],} \\
{[71],[83]}\end{array}$ \\
\hline Spinning & $\begin{array}{l}\text {-Electrospinning } \\
\text {-Emulsion spinning } \\
\text {-Solution blowing } \\
\text {-Dry-wet spinning }\end{array}$ & $\begin{array}{l}\text { Asphalt, } \\
\text { ceramics, } \\
\text { polymers }\end{array}$ & $\begin{array}{l}\text { Poly (vinylidene fluoride) } \\
\text { (PVDF), poly (methyl } \\
\text { methacrylate) } \\
\text { (PMMA)/polyacrylonitrile } \\
\text { (PAN) solutions, carbon } \\
\text { nanotubes }\end{array}$ & Relatively & $\begin{array}{l}\text {-Requires } \\
\text { specialized } \\
\text { equipment. } \\
\text {-Yields } \\
\text { randomized } \\
\text { network }\end{array}$ & $\begin{array}{l}{[86],} \\
{[88],[89],} \\
{[91],} \\
{[101]-} \\
{[103],} \\
{[108]}\end{array}$ \\
\hline
\end{tabular}

\subsection{Additive manufacturing}

The fabrication techniques described so far have shown efficiency for vascular self-healing, however, most of them are limited to orthogonal geometries or random formations. As topology optimization techniques advance, enhanced manufacturing capabilities are required to realize these geometries. AM is a layer-by-layer fabrication technique that has the ability to build more complex systems through an array of methods. The initial purpose of AM was to create prototypes for polymers, therefore most filament materials and design processes are tailored for applications with this material. However, the advancements in software, material and build volume capabilities yield potential to developing increasingly complex, large-scale structures that require minimal manual assembly and can be utilized across multiple industries, including the medical, automotive and aerospace fields [109]. Three of the primary AM printing techniques are discussed below, and include stereolithography (SLA), fused deposition modelling (FDM), and selective laser sintering (SLS); a summary of these three general methods is provided in Table 2.

\subsubsection{Stereolithography}

SLA works by using a computer controlled low-powered laser or a digital light projector in a layer-by-layer method to convert a photosensitive liquid into a solid state. A smooth outer surface can be developed by sanding, and overhangs are possible to construct as a result of the surrounding supporting liquid resin. Its disadvantages are that thin parts can warp and cured excess resin can block internal channels. Additional post-processing steps are usually required, and this method is limited to fewer materials relative to other methods. SLA has been used in tissue engineering applications to fabricate artificial blood vessel networks made 
from soft polymers with wall thicknesses between 3-18 $\mu \mathrm{m}$; it was found that wall thicknesses under $1 \mu \mathrm{m}$ collapsed due to the elasticity of the wall material [110], [111].

\subsubsection{Fused deposition modelling}

FDM is an extrusion-based printing method that has the advantage of a selection from a wide range of materials with the possibility to create relatively larger internal diameters. Similar to DWA previously described, this method relies on extruding a melted filament material rather than depositing droplets of a solution. Visser et al. [112] produced larger scale vasculatures (L x W x H = 67 x $42 \times 8 \mathrm{~mm}^{3}$ ) with diameters between 2-4 mm by printing polycaprolactone (PCL) and using PVA as a supporting material, which would later be dissolved in water (Figure 7).
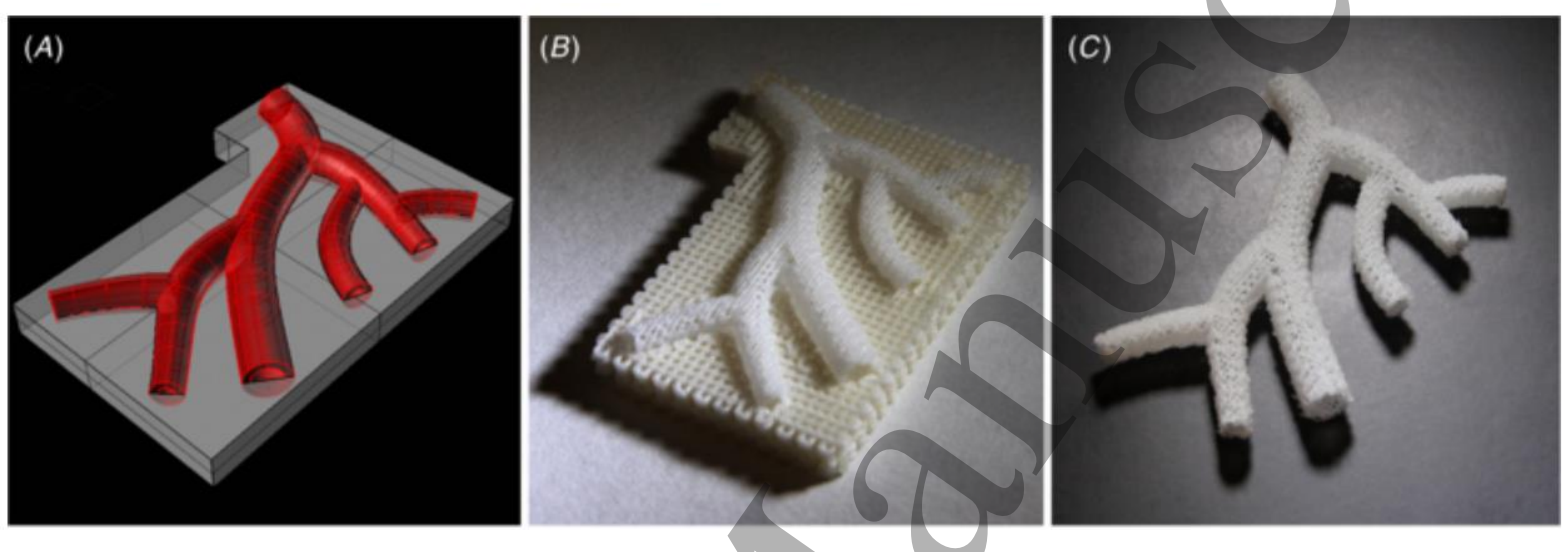

Figure 7. A) CAD design showing permanent (red) and sacrificial (gray) components, B) PCL shown in bright white and PVA in off-white, C) PCL structure after sacrificing the PVA support [112].

Compared to SLA, FDM does not produce smooth surfaces and creates a stair-stepping effect (Figure 8), leading to more irregularity that could affect flow behavior throughout the network. The stair-stepping effect can allow increased network bonding to a host material if the triggering mechanism relies on crack formation to fracture the network. Li et al. [18] used PLA as a filament material to print a complex vascular network obeying Murray's law, finding that the printed networks provided a rough surface and added friction that allowed strong adhesion to the cement matrix and would successfully break upon cracking to release the healing agent.
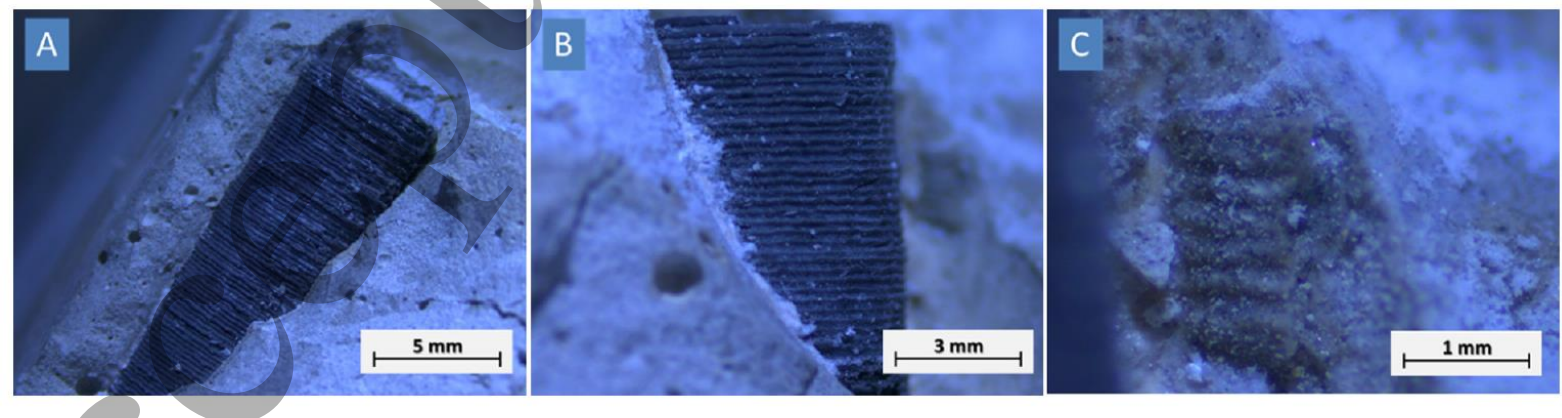

Figure 8. a) Microscope image of the connection between the vascular tubes and cement beams b) minerals between PLA tube and cement matrix, c) pattern that remained after tube was manually separated from cement matrix [18]. 


\subsubsection{Selective laser sintering}

SLS uses a laser to sinter powdered material (typically powder polymer, resin or metal) into a solidified layer of fused powder. The setup contains a powder reserve chamber and a printing chamber, which are heated to just below the melting temperature of the printing material. The printing chamber moves down as each layer is sintered while the reserve chamber moves up, adding a layer of powder with a leveling drum into the printing chamber. SLS can create complex hollow networks and does not require supports for large overhangs due to the surrounding unused powder, but is limited to a small number of materials due to the complex consolidation behavior and molecular diffusion process that occurs during sintering.

Commonly used powder materials for laser sintering are polycaprolactone (PCL) and polyamide (PA) [113], [114]. SLS is generally more expensive than other AM methods, as it requires costly postprocessing steps such as polishing and heat treatments due to poor surface finishing and dimensional inaccuracies during manufacturing. This aspect can be better controlled when fabricating scaffolds by properly selecting laser powder material, optimizing powder bed material and adjusting the laser scan speed [115]. Studies on fabricating tissue engineering scaffolds are reported in [116], [117].

Table 2. Overview of general additive manufacturing methods applicable, to vascular self-healing.

\begin{tabular}{|c|c|c|c|c|}
\hline AM Method & Supported Materials & Layer thickness range & Advantages & Disadvantages \\
\hline Stereolithography & $\begin{array}{l}\text { Radiation-curable resins or } \\
\text { photopolymers }\end{array}$ & $0.01-0.15 \mathrm{~mm}$ & $\begin{array}{l}\text { Detailed and } \\
\text { complex geometries } \\
\text { can be realized. }\end{array}$ & $\begin{array}{l}\text {-Post-processing steps } \\
\text { and UV curing are } \\
\text { required to full solidify } \\
\text { the printed part. } \\
\text {-Limited materials } \\
\text { available. } \\
\text {-Generally costlier to } \\
\text { produce a part. } \\
\text {-Resin used is toxic and } \\
\text { requires care when } \\
\text { handling. }\end{array}$ \\
\hline $\begin{array}{l}\text { Fused deposition } \\
\text { modelling }\end{array}$ & $\begin{array}{l}\text { Polymers, composites, cera } \\
\text { and metal slurries }\end{array}$ & $0.10-0.33 \mathrm{~mm}$ & $\begin{array}{l}\text {-Many low-cost } \\
\text { printers are } \\
\text { available and } \\
\text { materials are widely } \\
\text { available. } \\
\text {-Generally larger } \\
\text { build volumes are } \\
\text { available. Relatively } \\
\text { faster printing time. }\end{array}$ & $\begin{array}{l}\text {-Due to its lower } \\
\text { accuracy, finer design } \\
\text { details are difficult to } \\
\text { produce. } \\
\text {-Shrinkage can be } \\
\text { unpredictable. } \\
\text {-Support structures are } \\
\text { needed for large } \\
\text { overhangs. }\end{array}$ \\
\hline $\begin{array}{l}\text { Selective laser } \\
\text { sintering }\end{array}$ & $\begin{array}{l}\text { Polymers, composites, metals, } \\
\text { ceramics }\end{array}$ & $0.08-0.15 \mathrm{~mm}$ & $\begin{array}{l}\text {-Wide range of } \\
\text { available materials. } \\
\text {-No supporting } \\
\text { parts are required. } \\
\text {-Little post- } \\
\text { processing required. }\end{array}$ & $\begin{array}{l}\text {-High power } \\
\text { consumption is needed to } \\
\text { power the laser used for } \\
\text { sintering. } \\
\text {-Printer takes up a large } \\
\text { amount of space. }\end{array}$ \\
\hline
\end{tabular}

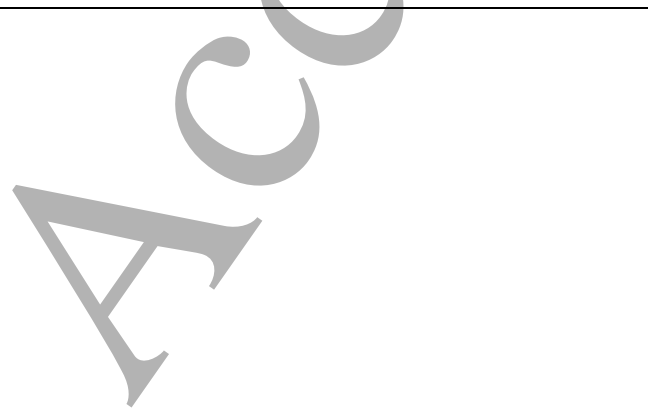




\subsubsection{Limitations in vascular network additive manufacturing}

While additive manufacturing techniques are greatly improving and allow greater complexities in network geometries to be realized, there are still a number of challenges to overcome to develop efficient self-healing vasculature.

Healing agent compatibility with the network wall material often limits which materials can be used for the network. For example, PLA, a widely used polymer filament material, contains moisture which will initiate curing of certain healing agents that react upon contact with water (i.e. cyanoacrylate). Material properties of the network are affected by the build orientation of the printing process. Simonelli et al. [118] investigated the tensile properties of a titanium alloy by printing Ti-6Al-4V in different orientations (flat, edge and vertical orientations), showing that the ductility and fracture mechanisms are dependent on the build orientation, with the edge-printed bars exhibiting the highest tensile properties.

Multiple challenges exist that limit the size of a printed structure. For SLA, the minimum structure size is limited to the light focusing and scattering of the equipment, printing resin absorbance and viscosity, as well as software control over printing parameters. Printing resolution, or the nozzle size for extrusion based additive manufacturing, can limit the accuracy, layer thickness, and surface smoothness of the printed network, therefore minimum wall thicknesses are currently restricted to the millimeter scale. Most filament materials used in FDM are not strong enough to create relatively large overhangs without the use of supporting structures, which need to be considered when developing the model for printing. Additionally, scaling up network configurations using additive manufacturing techniques are limited to the enclosed build volume of the printer, material strength properties of the network material, and time required to fabricate. This can be mitigated by creating connection joints and combining multiple pieces, however the joint design must consider implications for fluid flow. Larger enclosures or moving printing beds are other potential ways to overcome this limitation.

Further developments of additive manufacturing are inhibited by the limited amount of engineering standards, which are necessary for repeatedly reproducing reliable elements and for widespread adoption to industry. For polymer-based printing, there is limited information on its long-term performance as well as a lack of standards detailing the requirements for composition and material properties to be considered for filament materials. Some basic standards have been developed, such as ASTM F2792, ISO 17296, ISO/ASTM 52915-17, and ISO/ASTM 52921-13 [119]-[123], however a number of gaps exist among them, resulting in an incomplete set of design and testing requirements. In March 2016, a cross-sector coordinating partnership between America Makes and ANSI Additive Manufacturing Standardization Collaborative (AMSC) was created to help facilitate the coordination and development of consistent AM standards for industry use. They compiled gaps where no published specification exists for a particular industry need in an interactive, online portal that is regularly updated as standards are published. At the time of this paper, the AMSC roadmap indicated 93 gaps related to design, precursor materials, process control, certification, nondestructive evaluation, and maintenance of AM materials [124]. 


\section{Healing Agents and Mechanisms}

An ideal healing agent for a vascular network should have the ability to be contained within a supply system, be adequately mobile to flow to damaged zones, and resist crack re-opening. Sufficient viscosity of a healing agent is required so that it is not overly viscous, and a viscosity that is too low could cause a substantial loss of healing agent through macrocracks or pores within the matrix. Additionally, the healing agent should have equivalent or improved mechanical properties upon curing [60], [61]. Described here are healing agents, triggering mechanisms and fluid delivery mechanisms that have been employed for selfhealing in a number of experimental investigations across different materials. These include agents that have been previously employed in vascular networks as well as potential agents, which have been used in intrinsic or (micro)capsule self-healing systems, and are summarized in Table 3.

\subsection{Healing agents}

\subsubsection{One-component agents}

Cyanoacrylate (CA), or superglue, is a one-component adhesive with a relatively low viscosity that polymerizes when it interacts with moisture or air, and has been used in cementitious applications. At room temperature, a thin layer of cyanoacrylate can cure within one minute to form a rigid thermoplastic that has an excellent adhesion to a wide range of substrates [125]. Due to its faster curing times, CA may be a suitable agent for structures subjected to dynamic loading (i.e. bridges, off-shore and coastal structures) where cracks could open and close multiple times, however it is not a preferred method by contractors for field use due to its rapid curing time and care required while handling [126], has limited chemical and thermal stability, and has a relatively high material cost [125]. Additionally, the time it takes for CA to cure is dependent on the thickness of the layer; a difference of as little as $0.1 \mathrm{~mm}$ in thickness can have a significant impact on the curing profile [127]. The advantage of one-component adhesives is that they typically have a longer shelf life and do not require mixing of separate components. Its fast curing time has proved suitable for experimental investigations and numerical modelling of predicting healing and flow behavior [57], [59], [61].

Gergely et al. [128] examined different one-part ultraviolet (UV)-curable healing agents for vascular healing in polymeric coating systems. The healing agents react when exposed to sunlight and begin to solidify, and over time will gain enough hardness to fully repair the coating. Light-healing agents can require little to no human intervention for repair, however they are limited to healing surface cracks. UV-curable agents have also been studied by Davami et al. [129] in a polymeric material and by Song et al. [130] in a self-healing protective coating for concrete.

Alkaline silicates have been explored for self-healing in cementitious materials, and employed for vascular use [18], [64] to recover mechanical strength. Sodium silicate reacts with the Portlandite in the cementitious matrix and has a relatively slower reaction process than other agents employed, as well as a low viscosity. The mechanism that explains how silicates improve mechanical performance in cementitious materials is still debated in literature. The most accepted theory among researchers is that a portion of sodium silicate reacts with the 
available $\mathrm{Ca}^{2+}$ cations of the cement paste, producing calcium silicate hydrates $(\mathrm{C}-\mathrm{S}-\mathrm{H})$, while the remaining part of the sodium silicate crystallizes after the evaporation or the absorption of the water [18], [65], [131], [132]. Potassium silicate has been proposed as an alternative to sodium silicate due to its relatively lower viscosity. However, it was shown to yield a significantly lower bending strength relative to cementitious self-healing materials using sodium silicate [133]. This is potentially due to its lower viscosity, as it is possible that it was partially absorbed into the cement matrix and thereby limited the amount of healing agent available for crack repair. The long-term use and stability of alkaline silicates in selfhealing cementitious applications however have not yet been well explored.

Certain bacteria have been encapsulated as a crack repair technique for concrete specimens by inducing calcium carbonate precipitation upon interacting with air or water upon crack formation. These bacteria are naturally found in soil, sand, and minerals, and include Bacillus cohnii, Bacillus pasteurii, Bacillus lentus, and Bacillus sphaericus. Use of bacteria for selfhealing cementitious materials has been limited by high alkalinity of concrete, which prevents the growth of the bacteria, and it is therefore essential to protect the bacteria from the high $\mathrm{pH}$ in concrete, which can be mitigated by using capsules or porous carriers as a mechanism for immobilization of spores [134], [135].

\subsubsection{Multiple-component agents}

Dicyclopentadiene (DCPD) monomer with Grubbs' catalyst (a reactive transition metal) has been a well explored healing agent for polymeric applications, first reported by White et al. for a micro-capsule based approach [3], [40], [87], [136]-[138]. Ring-opening metathesis polymerization (ROMP) is activated as DCPD comes into contact with Grubb's catalyst that is embedded within an epoxy matrix, which then bonds the crack faces together. DCPD monomer has the advantage of not reacting in the presence of moisture and has a low viscosity, which are ideal characteristics of healing agents for vascular usage, however the catalyst is expensive and can drive costs up for full-scale production.

Bisphenol-A-based (BPA) epoxy has been used in a number of studies as a fast curing healing agent and because of its higher strength properties [101], [139], [140]. Two-component healing agents generally have a longer shelf-life that can better match that of the host material, and can also be renewed periodically throughout the duration of the lifetime. A large drawback to this healing agent is its high toxicity and environmental concerns, and alternatives can be more expensive and not provide the same strength and stiffness properties. Lee et al. [141] filled the cores of solution blown fibers with epoxy precursors (either BPA epoxy resin or a hardener stored separately) to demonstrate the successful prevention of crack propagation in stretched fiber-composite specimens.

Williams et al. [42] supplied a vascular network in a sandwich composite with a pre-mixed epoxy resin solution, comparing it to a two-part network where the epoxy and resin were administered separately in the two different networks. They found that both systems were able to fully recover the undamaged failure load after a healing event, however their design incorporated vertical risers that indicated an adverse effect on healing efficiency. To further investigate alternatives to single network specimens with monomer delivery, Toohey et al. 
[41] built a two-part vascular network in a brittle polymer coating where an epoxy resin and amine-based curing agent remained isolated in separate networks until crack formation occurs. The two-part network achieved up to 16 successful healing cycles, compared to seven repeated healing cycles in a single network filled with DCPD monomer. They found that although a two-part network can extend the number of successful healing cycles, it is limited to relying on the components mixing by diffusion, and shows more efficient healing when there is external manipulation of the specimen to promote mixing.

Methacrylate (MMA) is an acrylic-based material that has proven its efficiency in manual crack healing for concrete, and is able to resist penetration of chlorides and carbonation. It has been shown to decrease the water permeability in a cementitious material through autonomous crack healing in capsule-based healing applications. MMA was initially used as a three-part system by Dry and McMillan [106] and further developed by Van Tittelboom et al. into a two-part system that used compounds of MMA monomer with an initiator and activator [142].

PDMS has been employed for polymers in microfluidic devices and in medical applications due to its biocompatibility and good mechanical properties. PDMS is a flexible, twocomponent, silicon-based engineered material, comprising of a resin monomer and a curing agent, and has been used as a direct writing ink [143] in addition to a flowing healing agent. The two components of PDMS have been encased separately yia electrospinning to form the cores of self-healing fibers [88], [89], [101]. PDMS typically cures within 24-48 hours at room temperature, so it may not be a suitable agent for applications that would require shorter healing times.

White et al. [144] developed a two-stage polymer chemistry in PMMA specimens where the healing agent initially forms a shape-conforming gel and later polymerizes to a solid polymer, healing a damaged area of up to $35 \mathrm{~mm}$ in diameter. Isolated networks retained a gel catalyst and a monomer initiator, and would be triggered and released upon a damage event, filling damaged zones within 20 minutes and restoring mechanical function within three hours. Twostage healing action was also investigated by Wang et al. [145] in a microcapsule self-healing system in concrete, where polyurethane and bacteria were released upon crack formation. Polyurethane would first polymerize and the bacteria would precipitate calcite into the pores of the polyurethane to increase its density.

Table 3. Overview of healing agents applicable to vascular self-healing.

53
${ }^{5}$ UV-curing
7

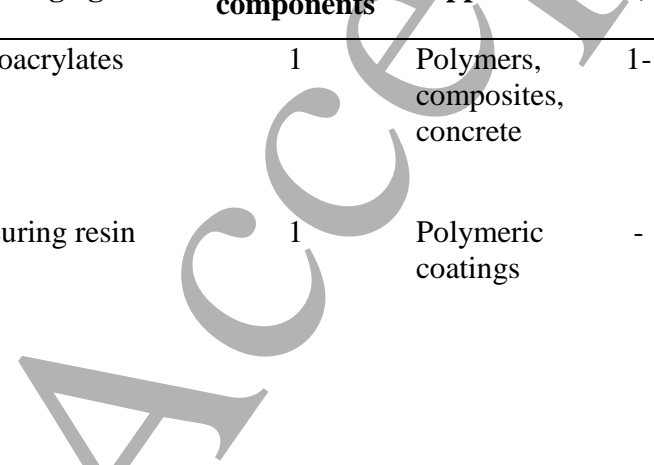

$(\mathbf{m P a s} @$
$\left.\mathbf{2 0}{ }^{\circ} \mathbf{C}\right)$
$1-10$

\begin{tabular}{llllll}
$\begin{array}{c}\text { Curing } \\
\text { time }\end{array}$ & $\begin{array}{c}\text { Way of } \\
\text { curing }\end{array}$ & $\begin{array}{l}\text { Shelf-life } \\
\text { (months) }\end{array}$ & Advantages & Disadvantages & Ref. \\
\hline $5-15$ & Moisture & 12 & -Low viscosity & -Curing time is & {$[12]$}
\end{tabular}

$\mathrm{sec}$ too fast for [17],

practical applications

-Feasible for

-Little to no human intervention needed for dosing

$$
\text { limited }
$$
applications (restricted to surface-level healing) 


\subsection{Healing agent triggering mechanisms}

\subsubsection{Triggering by network fracture}

Crack formation is the most common triggering mechanism to release a healing agent from a vascular network into a host material. It relies on the brittleness of the embedded network to fracture upon damage as well as having sufficient bonding to the surrounding host matrix material. Once a crack occurs, the healing agent would either be delivered by capillary action if it is contained within a closed network, or trigger healing agent delivery via embedded sensors in the host material that detect damage or a change in pressure.

Fracture of a vascular network to release the healing agent causes permanent damage to common network material, thus limiting the number of healing cycles it can provide. If a healing agent has a low enough viscosity, it may seep back into the broken network and cause blockage. In order to flush the network from any remaining healing agent solution, Minnebo et al. [64] pumped air through their vascular network embedded in a concrete specimen.

Preventing thrombosis in vascular networks is a topic of research interest, and most 3D 
vascular designs have relied on sufficient redundancy in a network so enough channels are available for fluid flow [36]. In her PhD thesis, Qamar [153] suggests a porous network design to limit thrombosis by constructing a flexible network, rather than brittle, which debonds from the surrounding matrix upon network fracture and releases a healing agent through the pores. The network would remain intact after a healing event and be available for multiple healing events, however it may require a system of valves or channel cleaning following healing agent release to fully prevent network blocking.

\subsubsection{Self-sensing methods}

Kousourakis et al. developed an autonomous healing system that was based on the comparative vacuum monitoring (CVM) technique, a structural health monitoring (SHM) method [46][154]. Linear tubes of $<1 \mathrm{~mm}$ in diameter were located between layers of a composite laminate. Air was removed in every other tube by vacuum to place them in a lowpressure state, while the intermediary tubes remained at ambient air pressure. As a crack would grow and pass through multiple tubes, a change in pressure would be detected that would then trigger the release of a healing agent from an external reservoir. Norris et al. [155] demonstrated this system in a structural FRP composite and compared it to a circulatory network that mimics blood flow, however, this approach continuously circulated the healing agent rather than having relied on damage detection. The pressure detecting vessels were only limited to one healing event as they would become blocked upon polymerization of the healing agent following damage. The triggered healing approach resulted in $94 \%$ recovery of post-impact compression strength, and the circulatory method lead to a $100 \%$ recovery. Trask et al. [156] expanded on this scheme by developing a system where every other tube is subject to positive pressure, and the release of pressure following delamination would trigger the healing agent delivery to the damaged zone.

Gergely et al. [128] reported an autonomous healing agent storage and release system for a protective coating, where the healing agent remains stored in the network until abrasion completely removes the protective coating. The embedded vasculature would then release a finite amount of one-part healing agent to the surface, which regenerates the protective coating when exposed to UV light (as previously described).

Another self-diagnosing vascular healing system was developed by Nishiwaki et al. [157] where they applied an ethylene vinyl acetate (EVA) film on organic film pipes for selective heating. The self-diagnosing composite tubes, placed below the pipes containing healing agent, consisted of fiber reinforced composites and electro-conductive materials which would increase in electric resistance once subjected to strain due to crack formation. This added resistance would heat the concrete around the crack to the melting point of the film surrounding the pipe, which would then release the contained epoxy resin healing agent.

\subsection{Delivery Mechanisms}

\subsubsection{Capillary flow}

Contained healing agents in a closed vascular network are immediately released upon crack formation, relying on capillary and gravitational forces to transport the healing agent through the crack plane. When relying only on capillary forces to drive a healing agent through a 
network and into a crack, the flow efficiency depends on the network channel diameter, crack width and viscosity of the healing agents [107].

\subsubsection{Pressurized networks}

Pumping of healing agents through networks has been used overcome the limitation of blockage in channels after buildup of healed material in the crack plane after multiple loading cycles and is used to improve fluid flow throughout the system. Hamilton et al. [158] achieved almost full recovery of fracture toughness in an epoxy matrix after 15 damagehealing cycles, and demonstrated more repeatability than unpressurized samples, which saw mechanical recovery up until six cycles. Cementitious vascular systems relying on pumping mechanisms to improve fluid flow have also been explored in [18], [59].

\subsubsection{Expansive agents}

Foaming agents have been developed for cementitious capsule-based self-healing materials [159], [160] and implemented in a vascular system by Minnebo et al. using polyurethane [64], as they have potential of greater diffusion depths due to their expansive characteristics. Polyurethane can be obtained either as a one- or two-component foaming healing agent. Onecomponent polyurethane quickly expands upon contact with moisture. For two-component polyurethane, one part of the compound consists of a prepolymer of polyurethane and foams when in contact with moisture, and the second is an accelerator that shortens the reaction time. The expanding foaming reaction can lead to an increase in volume of 25-30 times and creates a driving force that pushes the healing agent outside of the encapsulation system upon crack formation.

\section{Characterization and Evaluation of Self-Healing Performance}

Assessment of self-healing is shown by recovery of mechanical properties or tightness of the host material, and can be measured by changes in stiffness, tensile strength, adhesion, and permeability, depending on the nature of the host material. These properties can be measured in the following described testing methods, and are summarized in Table 4.

Three- and four-point bending tests are used to measure a material's stiffness and strength, using beam specimens with a uniform rectangular cross-section. Three-point bending tests use notched specimens to promote guided cracking, and four-point bending tests induce multiple, random cracking that closely simulates realistic loading conditions. Specimens are loaded at least twice to measure performance before and after healing [65], [133], [161], [162].

Self-healing in adhesives, such as BPA epoxies, can be evaluated by an adhesion (blister) test, which is a measure of energy of adhesion. A shaft-loaded blister test (SLBT) applies a load at the center of the test specimen to cause delamination at the membrane-substrate interface, where the adhesion energy is defined by the applied loading and blister width [163], and has been used by $\mathrm{Na}$ et al. [164] to measure the adhesion energy of electrospun PVDF fibers (Figure 9). 
(a)

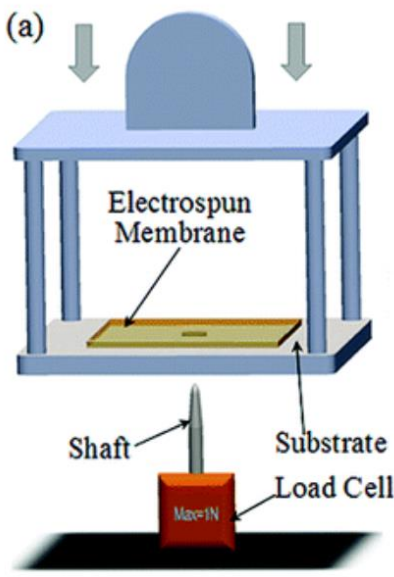

(b)

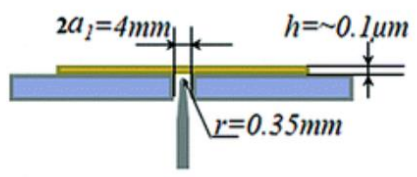

(c)

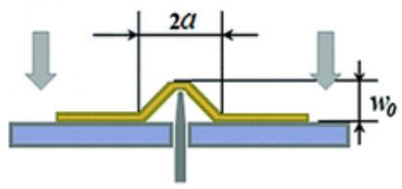

Figure 9. Loading apparatus and testing scheme for SLBT [164].

The adhesion energy is determined by:

$$
T=\frac{3}{8}\left(\frac{1}{\pi^{4} E h}\right)^{1 / 3}\left(\frac{P}{a}\right)^{4 / 3} \quad(\text { Equation 2) }
$$

where $\mathrm{T}$ is the adhesion energy $\left(\mathrm{J} / \mathrm{m}^{2}\right), \mathrm{E}$ is Young's modulus of the membrane (MPa), $\mathrm{h}$ is the thickness of the membrane $(\mathrm{mm}), \mathrm{P}$ is the peak load $(\mathrm{N})$ and a is the radius $(\mathrm{mm})$ of the blistered area during peak loading [101].

Acoustic emission (AE) is a non-destructive evaluation technique that can be used to investigate cracking in real-time, using transducers that continuously sense acoustic waves generated by crack formation. Characteristics of these waves, such as number of hits, amplitudes, velocity, frequency, and AE energy, can be used to determine the type and magnitude of damage [44], [147], [165], [166]. An ultrasonic pulse velocity test is another non-destructive technique that measures the time it takes for a vibrational energy pulse to travel through a material, and has been used to monitor the evolution of the healing process in concrete samples [58], [167], [168].

Comparative vacuum modelling is a real-time structural health monitoring method to nondestructively evaluate cracks in materials. A flow meter is connected to a sensor composed of a series of closed tubes which are placed on the surface of the material where damage is expected. The tubes alternate between ambient air pressure and vacuum. Crack formation along the surface causing air to leak into the vacuum tubes, which then triggers the sensor; if no damage develops, then the flow meter will remain at a stable level. A rate of flow would correspond to a magnitude of damage [46], [154]. An advantage to using this method is that it does not require the use of expensive sensors. 
Table 4. Testing methods used to assess healing and mechanical recovery of self-healing materials.

\begin{tabular}{|c|c|c|c|c|c|}
\hline Type & Test Method & Matrix material & Purpose & Limitations & References \\
\hline \multirow[t]{6}{*}{$\begin{array}{l}\text { Mechanical } \\
\text { property regain }\end{array}$} & Bending test & $\begin{array}{l}\text { Composites, } \\
\text { polymer, concrete }\end{array}$ & $\begin{array}{l}\text { Measure regain in } \\
\text { stiffness and/or strength }\end{array}$ & $\begin{array}{l}\text { Influenced by size } \\
\text { and curing of the } \\
\text { specimen }\end{array}$ & $\begin{array}{l}{[59],[65],} \\
{[133],[161],} \\
{[162],[169]} \\
{[171]}\end{array}$ \\
\hline & Tensile test & $\begin{array}{l}\text { Composites, } \\
\text { polymer, concrete }\end{array}$ & & $\begin{array}{l}\text { Influenced by } \\
\text { moisture content of } \\
\text { the specimen }\end{array}$ & $\begin{array}{l}{[44],[108],} \\
{[172]-[174]}\end{array}$ \\
\hline & Adhesion test & Polymer & $\begin{array}{l}\text { Determine ability to } \\
\text { adhere to another material }\end{array}$ & $\begin{array}{l}\text { Substrate material } \\
\text { can influence } \\
\text { deformation and } \\
\text { bonding behavior }\end{array}$ & $\begin{array}{l}{[101],[163],} \\
{[175]}\end{array}$ \\
\hline & $\begin{array}{l}\text { Acoustic } \\
\text { emissions }\end{array}$ & $\begin{array}{l}\text { Composites, } \\
\text { polymer, concrete }\end{array}$ & $\begin{array}{l}\text { Detect cracking and } \\
\text { measure regain in energy }\end{array}$ & $\begin{array}{l}\text { Sensitive to ambient } \\
\text { noise and needs to } \\
\text { be filtered }\end{array}$ & $\begin{array}{l}{[44],[147],} \\
{[165],[166]}\end{array}$ \\
\hline & $\begin{array}{l}\text { Ultrasonic } \\
\text { pulse velocity } \\
\text { (UPV) }\end{array}$ & Concrete & $\begin{array}{l}\text { Detect cracking and } \\
\text { estimate compressive } \\
\text { strength }\end{array}$ & $\begin{array}{l}\text { Can be affected by } \\
\text { reinforcement, w/c } \\
\text { ratio, and transducer }\end{array}$ & $\begin{array}{l}{[58],[167],} \\
{[168]}\end{array}$ \\
\hline & $\begin{array}{l}\text { Comparative } \\
\text { vacuum } \\
\text { modelling } \\
(\mathrm{CVM})\end{array}$ & Composites & $\begin{array}{l}\text { Location and magnitude } \\
\text { of crack formation }\end{array}$ & $\begin{array}{l}\text { Restricted to } \\
\text { surface cracking }\end{array}$ & {$[46],[154]$} \\
\hline $\begin{array}{l}\text { Water tightness } \\
\text { recovery }\end{array}$ & $\begin{array}{l}\text { Water } \\
\text { permeability }\end{array}$ & Concrete & $\begin{array}{l}\text { Flow of water through } \\
\text { cracks }\end{array}$ & $\begin{array}{l}\text {-Dependent upon } \\
\text { crack induction } \\
\text {-Sensitive to } \\
\text { specimen } \\
\text { composition }\end{array}$ & $\begin{array}{l}{[18],[59],} \\
{[169]}\end{array}$ \\
\hline \multirow[t]{3}{*}{$\begin{array}{l}\text { Visualization } \\
\text { and } \\
\text { characterization }\end{array}$} & $\begin{array}{l}\text { Optical } \\
\text { microscopy }\end{array}$ & $\begin{array}{l}\text { Composites, } \\
\text { polymer, concrete }\end{array}$ & $\begin{array}{l}\text { Visualization of crack } \\
\text { closure }\end{array}$ & $\begin{array}{l}\text { Effectiveness relies } \\
\text { on the microscope } \\
\text { resolution }\end{array}$ & $\begin{array}{l}{[18],[44],} \\
{[155]}\end{array}$ \\
\hline & $\begin{array}{l}\text { Digital image } \\
\text { correlation } \\
\text { (DIC) }\end{array}$ & $\begin{array}{l}\text { Composites, } \\
\text { polymer, concrete }\end{array}$ & & $\begin{array}{l}\text {-Sensitivity to } \\
\text { external light } \\
\text { sources } \\
\text {-Restricted to } \\
\text { surface cracking }\end{array}$ & $\begin{array}{l}{[12],[27],} \\
{[83],[176]}\end{array}$ \\
\hline & $\begin{array}{l}\text { Scanning } \\
\text { electron } \\
\text { microscopy } \\
\text { (SEM) }\end{array}$ & $\begin{array}{l}\text { Composites, } \\
\text { polymer, concrete }\end{array}$ & $\begin{array}{l}\text { Provide high resolution } \\
\text { morphological and } \\
\text { compositional information }\end{array}$ & $\begin{array}{l}\text {-Generally } \\
\text { expensive } \\
\text {-Careful sample } \\
\text { preparation required }\end{array}$ & $\begin{array}{l}{[18],[69],} \\
{[87],[91],} \\
{[94]}\end{array}$ \\
\hline
\end{tabular}

Durability in cementitious materials is typically measured by water permeability and water absorption tests, and has been used by a number of studies as a measure of self-healing ability [149], [159], [177], [178]. Excessive cracking in reinforced concrete can cause water or aggressive substances to seep through and corrode rebar, which in turn weakens the structure and reduces its tensile strength. Water permeability tests can be used to measure the change in flow of water through discrete cracks prior and following a healing event. 
A number of visualization tools have been used to measure and characterize self-healing in multiple materials, including optical microscopy, digital image correlation (DIC), and scanning electron microscopy (SEM). Optical microscopy [18], [44], [155] and DIC [12], [27], [83], [176] have been used to visualize and measure crack closure. DIC works by taking multiple images of a crack generation along a surface, where one point in an image is correlated to consecutive images to measure a displacement. SEM uses a focused beam of high-energy electrons to generate signals on a solid specimen, which are used as information on its morphology, chemical composition and microstructure [179], giving visual insight on healing performance [18], [69], [87], [91], [94].

\section{Large-Scale Applications}

Large-scale applications of self-healing vascular materials are limited, however some preliminary site trials of vascular networks in concrete have been performed. Dry et al. [180] expanded self-healing efficiency testing from beams [17] to small one-story lab-size frames with the potential for scaling up [181]. Glass tubes were embedded in one-story structural frames (approx. $24 \mathrm{~cm}$ wide by $19 \mathrm{~cm}$ tall) subjected to earthquake loading and connected to an external supply. They demonstrated that cracks repaired by the healing agent would cause other areas to crack when stressed, resulting in cracking around the structure. This used much of the material's strength, but was able to prevent overall catastrophic failure. Larger size elements were investigated by her group in [182], where they embedded glass tubes in a concrete bridge deck (approx. $7.6 \mathrm{~cm}$ x $122 \mathrm{~cm}$ x $610 \mathrm{~cm}$ ).

More recently, the Materials for Life (M4L) research project conducted the first in-situ site trials for self-healing concrete in the UK [183], including a test on a 2D vascular network embedded in a wall panel $(1.8 \mathrm{~m} \times 1.0 \mathrm{~m} \times 0.15 \mathrm{~m})$, verifying its ability to repeatedly distribute a healing agent through the network to repair damage. Tsangouri et al. [184] investigated the healing feasibility of a planar yascular network embedded within a real-size concrete slab ( $4.0 \mathrm{~m} \times 1.0 \mathrm{~m} \times 0.20 \mathrm{~m}$ ) loaded under four point bending by incorporating a number of advanced monitoring methods, including AE, DIC, and visual crack inspection (Figure 10). They found that local healing was obtained with a pulse velocity regain of up to $100 \%$, however repair was limited for larger cracks with widths over $0.5 \mathrm{~mm}$. Most studies of scaling up networks are still executed in a lab setting, highlighting the need for improving design techniques and manufacturing methods for in-situ application. 


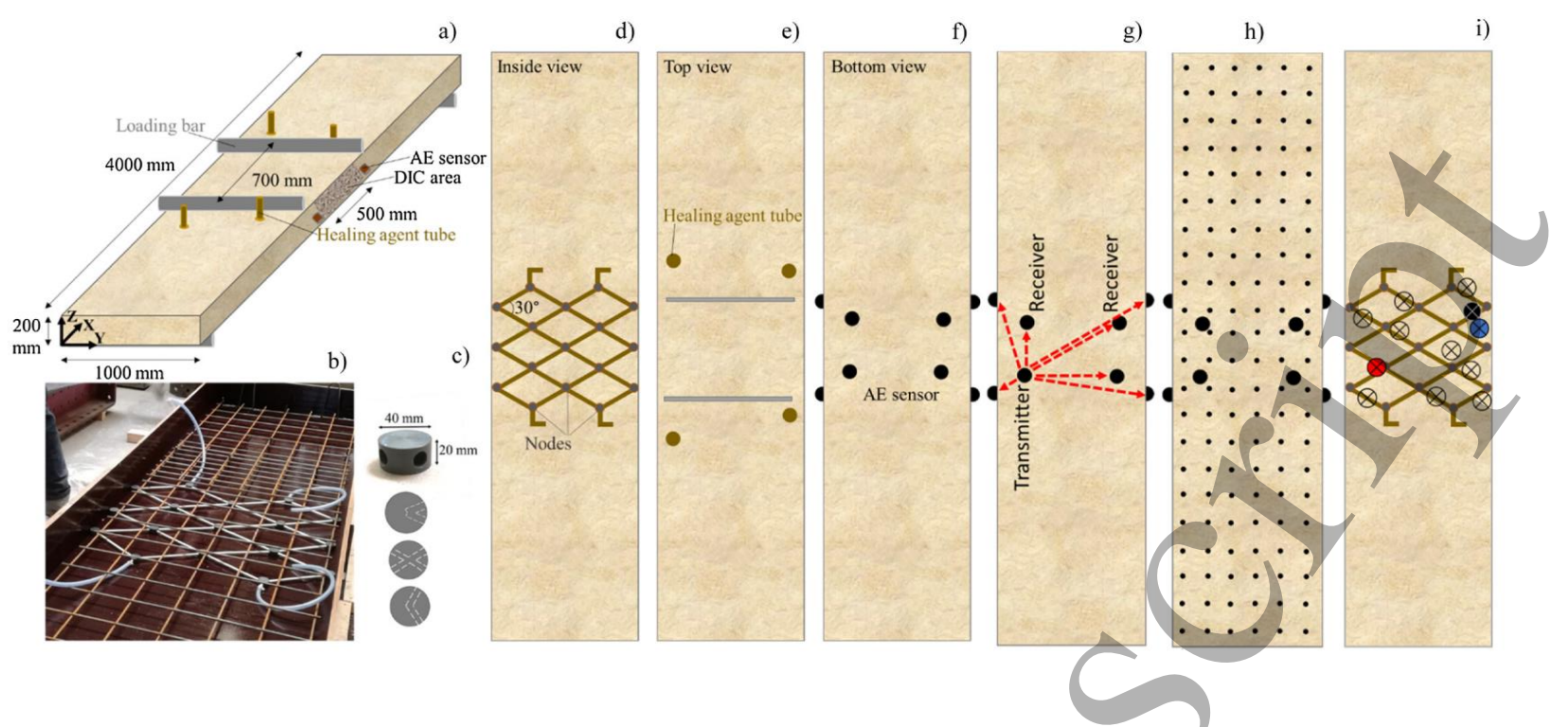

Figure 10. a) Loading set-up and slab dimensions; b) Steel rebars mesh and vascular network capsules embedded into the slab mold; c) Node and their geometry; d) Inside view of the slab where the vascular network is illustrated; e) Healing agent deposit tubes, $f$ ) AE transducers position; $g$ ) Transmitter-receiver illustration of AE transducers used for ultrasound pulse velocity measurements; h) Hammer tapping points throughout the bottom of the slab; i) Core drilling positions [184].

Further full-scale trials will likely be seen once successful repeated healing ability is demonstrated, as well as when capabilities for large scale additive manufacturing are enhanced. Replicating laboratory scale tests will also require a more autonomous material with a damage sensor to initiate and terminate healing, so that manual intervention for repair is reduced.

A detailed life cycle analysis of vascular self-healing, as well as indications that the upfront costs of this system are less than the maintenance costs of a traditional (not self-healing) system, will also need to be explored to justify its use to potential stakeholders. Life cycle studies on other self-healing systems show that there is potential for improved durability, reduced environmental impact and overall cost savings [185]-[187], however a full life cycle cost analysis cannot be complete until more information is collected from trials on real systems. Current lab-scale investigations utilize commercially available healing agents and network fabrication methods, however the optimal and cost-effective healing agent and network combination for each type of material has not been well-defined and can be a topic of future research.

\section{Future Perspectives}

The main advantage of a vascular network over other healing methods is that it can remain available for more than one healing cycle. Design methodologies that maximize the amount of healing and thus hold the most promise for further developing self-healing vasculature include 1) having sufficient redundancy of network branches while not compromising the structural integrity of the host material, and 2) flexible networks that do not rely on fracture to release a healing agent, thus available for an indefinite number of healing cycles. Either of these 
methods can leverage evolutionary algorithms that could further optimize the network design by considering multiple parameters and variables.

AM techniques have the ability to fabricate complex geometries that traditional machining methods lack while reducing the amount of manual assembly. Although AM technologies have great potential for advancing the manufacturing process of self-healing vasculature, they come with significant limitations that still need to be overcome. Three-dimensional design modeling and printing techniques require extensive training, and the lack of standardized printing methods and guidelines hinders the user from efficiently realizing a model.

Additionally, filament material properties can be inconsistent among different manufacturers, and measured properties can differ from the material datasheets, making extensive preliminary testing necessary prior to fabricating the final model [188].

Other gaps in research include the development of guidelines for healing agent selection, which would aim for compatibility with the host material as well as minimize reactivity with the network wall material to avoid blockages. Healing agent curing behavior can depend on the quantity administered as well as the substrate it is applied to, and selection criteria would aid industry professionals and researchers in the advancement of this self-healing method. A number of researchers have mentioned that a larger void volume fraction imposed by an embedded network can negatively affect the mechanical behavior of the host material [24], [48], [189], however quantifying that negative attribute for different host materials has yet to be studied and should be a topic of future research. Additionally, once repeated healing ability is developed in a vascular self-healing system, this technology can be applied from research to full-scale practical applications.

Each of the gaps previously described reaches different scientific communities and will require a collaboration among these various fields of research, as well as among the researchers focusing on different material classes. Industry professionals would first need to identify which applications are best suited for vascular healing. Experts in chemistry or material science would need to develop or identify ideal healing agents for each specific host material that can be readily utilized in vascular network applications, having sufficient viscosity for the effective filling of cracks and improving mechanical or durability properties. Computer scientists could further investigate optimization techniques for network design that improve fluid flow, allow for sufficient redundancy and minimize the impact on the host material's original properties. Designers of vascular networks would then need to synthesize this multidisciplinary expertise to deliver the optimal self-healing vascular network for their particular application.

\section{Conclusions}

While this topic is still in its infancy, the development of self-healing vasculature has made progress in terms of determining suitable healing agents and preliminary network designs, and shows enhanced performance compared to other self-healing techniques given its ability to continuously heal over multiple damage events and address multiple scales of damage.

So far, Murray's Law has been used to determine optimal channel diameters and branching angles, and some advanced computational methods have been leveraged to optimize topology 
and channel sizes while considering constrictive parameters. Blockages within networks are still a major limitation of the healing efficiency of a vascular network, and further developments in network designs will need to reduce or eliminate them. This could be achieved by closing off the network once fractured or employ self-healing network materials to prevent a healing agent from seeping back in.

Most fabrication techniques are limited to planar network configurations, and some such as electrospinning and solution blowing techniques yield randomized network designs. However, more complex geometries and configurations can be realized with the increasing improvements made in additive manufacturing techniques. Design and manufacturing for AM is a continuously evolving topic that is of interest to the development of complex, biomimetic self-healing networks. To effectively implement this healing approach at an industrial scale, will require further collaboration between chemists, material scientists, computer scientists, and additive manufacturing specialists.

\section{Acknowledgements}

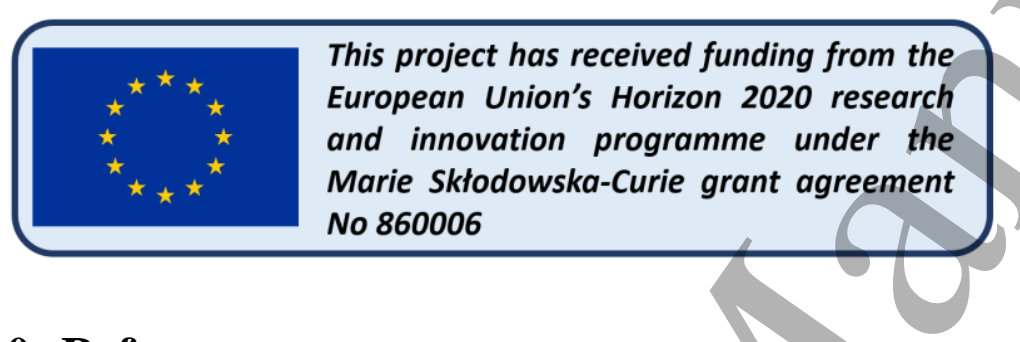

\section{References}

[1] S. R. White, B. J. Blaiszik, S. L. B. Kramer, S. C. Olugebefola, J. S. Moore, and N. R. Sottos, "Selfhealing polymers and composites," Am. Sci., 2011,doi: 10.1511/2011.92.392.

[2] S. van der Zwaag, Self-Healing Materials: An Alternative Approach to 20 Centuries of Materials Science. Dordrecht: Springer-Verlag, 2007.

[3] S. R. White, N. R. Sottos, P. H. Geubelle, J. S. Moore, M. R. Kessler, S. R. Sriram, E. N. Brown, and S. Viswanathan, "Autonomic healing of polymer composites," Nature, vol. 409, no. 6822, pp. 794-797, 2001, doi: 10.1038/35057232.

[4] C. J. Hansen, W. Wu, K. S. Toohey, N. R. Sottos, S. R. White, and J. A. Lewis, "Self-healing materials with interpenetrating microvascular networks," Adv. Mater., vol. 21, no. 41, pp. 4143-4147, Nov. 2009, doi: 10.1002/adma.200900588.

[5] J. B. Ferguson, B. F. Schultz, and P. K. Rohatgi, "Self-healing metals and metal matrix composites," JOM. 2014, doi: 10.1007/s11837-014-0912-4.

[6] V. K. Thakur and M. R. Kessler, "Self-healing polymer nanocomposite materials: A review," Polymer (Guildf)., 2015, doi: 10.1016/j.polymer.2015.04.086.

[7] Y. Yang and M. W. Urban, "Self-healing polymeric materials," Chem. Soc. Rev., 2013, doi: 10.1039/c3cs60109a.

[8] D. L. Taylor and M. in het Panhuis, "Self-Healing Hydrogels," Advanced Materials. 2016, doi: 10.1002/adma.201601613.

[9] Y. Wang, C. K. Adokoh, and R. Narain, "Recent development and biomedical applications of selfhealing hydrogels," Expert Opinion on Drug Delivery. 2018, doi: 10.1080/17425247.2017.1360865.

[10] Q. Zhang, L. Liu, C. Pan, and D. Li, "Review of recent achievements in self-healing conductive materials and their applications," Journal of Materials Science. 2018, doi: 10.1007/s10853-017-1388-8.

[11] Y. Yang, X. Ding, and M. W. Urban, "Chemical and physical aspects of self-healing materials," Progress in Polymer Science. 2015, doi: 10.1016/j.progpolymsci.2015.06.001.

[12] K, Van Tittelboom and N. De Belie, "Self-Healing in Cementitious Materials-A Review," Materials (Basel)., pp. 2182-2217, 2013, doi: 10.3390/ma6062182. 
[13] M. Zhu, J. Liu, L. Gan, and M. Long, "Research progress in bio-based self-healing materials," Eur. Polym. J., vol. 129, no. March, p. 109651, 2020, doi: 10.1016/j.eurpolymj.2020.109651.

[14] A. P. Mouritz, M. K. Bannister, P. J. Falzon, and K. H. Leong, "Review of applications for advanced three-dimensional fibre textile composites," Compos. Part A Appl. Sci. Manuf., 1999, doi: 10.1016/S1359-835X(99)00034-2.

[15] A. Cuvellier, A. Torre-Muruzabal, G. Van Assche, K. De Clerck, and H. Rahier, "Selection of healing agents for a vascular self-healing application," Polym. Test., 2017, doi: 10.1016/j.polymertesting.2017.07.013.

[16] J. D. Rule, N. R. Sottos, S. R. White, B. J. Blaiszik, S. L. B. Kramer, S. C. Olugebefola, J. S. Moore, and N. R. Sottos, "Self-healing Polymers and Composites Capsules , circulatory systems and chemistry allow materials to fix themselves," Am. Sci., 2011, doi: 10.1511/2011.92.392.

[17] C. Dry, "Matrix cracking repair and filling using active and passive modes for smart timed release of chemicals from fibers into cement matrices," Smart Mater. Struct., vol. 3, no. 2, pp.118-123, 1994, doi: 10.1088/0964-1726/3/2/006.

[18] Z. Li, L. R. De Souza, C. Litina, A. E. Markaki, and A. Al-tabbaa, “A novel biomimetic design of a 3D vascular structure for self-healing in cementitious materials using Murray 's law," Mater. Des., vol. 190, p. 108572, 2020, doi: 10.1016/j.matdes.2020.108572.

[19] A. Bejan, "Constructal-theory network of conducting paths for cooling a heat generating volume," Int. J. Heat Mass Transf., 1997, doi: 10.1016/0017-9310(96)00175-5.

[20] A. Bejan, "Street network theory of organization in nature," J. Adv. Transp., vol. 30, no. 2, pp. 85-107, 1996, doi: 10.1002/atr.5670300207.

[21] A. F. Miguel, "Toward an optimal design principle in symmetric and asymmetric tree fl ow networks," $J$. Theor. Biol., vol. 389, pp. 101-109, 2015, doi: 10.1016/j.jtbi.2015.10.027.

[22] A. Bejan, S. Lorente, and K. M. Wang, "Networks of channels for self-healing composite materials," J. Appl. Phys., 2006, doi: 10.1063/1.2218768.

[23] K. M. Wang, S. Lorente, and A. Bejan, "Vascularization with grids of channels: Multiple scales, loops and body shapes," J. Phys. D. Appl. Phys., 2007, doi: 10.1088/0022-3727/40/15/057.

[24] A. M. Aragón, R. Saksena, B. D. Kozola, P. H. Geubelle, K. T. Christensen, and S. R. White, "Multiphysics optimization of three-dimensional microvascular polymeric components," J. Comput. Phys., 2013, doi: 10.1016/j.jcp.2012.07.036.

[25] S. Lorente and A. Bejan, "Vascularized smart materials: Designed porous media for self-healing and self-cooling," J. Porous Media, 2009, doi: 10.1615/JPorMedia.v12.i1.10.

[26] S. Soghrati, P. R. Thakre, S. R. White, N. R. Sottos, and P. H. Geubelle, "Computational modeling and design of actively-cooled microvascular materials," Int. J. Heat Mass Transf., 2012, doi: 10.1016/j.ijheatmasstransfer.2012.05.041.

[27] A. R. Hamilton, N. R. Sottos, and S. R. White, "Local strain concentrations in a microvascular network," 2010, doi: 10.1007/s11340-009-9299-5.

[28] J. Lee, S. Lorente, and A. Bejan, "Transient cooling response of smart vascular materials for selfcooling," J. Appl. Phys., 2009, doi: 10.1063/1.3068323.

[29] L. A. O. Rocha, S. Lorente, and A. Bejan, "Tree-shaped vascular wall designs for localized intense cooling,” Int. J. Heat Mass Transf., 2009, doi: 10.1016/j.ijheatmasstransfer.2009.03.003.

[30] E. Cetkin, S. Lorente, and A. Bejan, "Hybrid grid and tree structures for cooling and mechanical strength," J. Appl. Phys., 2011, doi: 10.1063/1.3626062.

[31] O. Yenigun and E. Cetkin, "Experimental and numerical investigation of constructal vascular channels for self-cooling: Parallel channels, tree-shaped and hybrid designs," Int. J. Heat Mass Transf., 2016, doi: 10.1016/j.ijheatmasstransfer.2016.08.074.

[32] K. H. Cho, J. Lee, M. H. Kim, and A. Bejan, "Vascular design of constructal structures with low flow resistance and nonuniformity," Int. J. Therm. Sci., 2010, doi: 10.1016/j.ijthermalsci.2010.07.009.

[33] C. J. Norris, I. P. Bond, and R. S. Trask, "Interactions between propagating cracks and bioinspired selfhealing vascules embedded in glass fibre reinforced composites," Compos. Sci. Technol., 2011, doi: 10.1016/j.compscitech.2011.01.027.

[34] C. J. Norris, I. P. Bond, and R. S. Trask, "The role of embedded bioinspired vasculature on damage formation in self-healing carbon fibre reinforced composites," Compos. Part A Appl. Sci. Manuf., vol. 42, no. 6, pp. 639-648, 2011, doi: 10.1016/j.compositesa.2011.02.003.

[35] H. R. Williams, R. S. Trask, A. C. Knights, E. R. Williams, and I. P. Bond, "Biomimetic reliability strategies for self-healing vascular networks in engineering materials," J. R. Soc. Interface, 2008, doi: 10.1098/rsif.2007.1251.

[36] S. J. Pety, M. H. Y. Tan, A. R. Najafi, A. C. Gendusa, P. R. Barnett, P. H. Geubelle, and S. R. White, 
"Design of redundant microvascular cooling networks for blockage tolerance," Appl. Therm. Eng., 2018, doi: 10.1016/j.applthermaleng.2017.10.094.

37] T. F. Sherman, "On connecting large vessels to small. The meaning of Murray’s law.," J. Gen. Physiol., 1981, doi: 10.1085/jgp.78.4.431.

[38] R. S. Trask, G. J. Williams, and I. P. Bond, "Bioinspired self-healing of advanced composite structures using hollow glass fibres,” J. R. Soc. Interface, 2007, doi: 10.1098/rsif.2006.0194.

[39] R. S. Trask, H. R. Williams, and I. P. Bond, "Self-healing polymer composites: Mimicking nature to enhance performance," Bioinspiration and Biomimetics, vol. 2, no. 1, 2007, doi: 10.1088/17483182/2/1/P01.

[40] K. S. Toohey, N. R. Sottos, J. A. Lewis, J. S. Moore, and S. R. White, "Self-healing materials with microvascular networks," Nat. Mater., vol. 6, no. 8, pp. 581-585, 2007, doi: 10.1038/nmat1934

[41] K. S. Toohey, C. J. Hansen, J. A. Lewis, S. R. White, and N. R. Sottos, "Delivery of two-part selfhealing chemistry via microvascular networks," Adv. Funct. Mater., 2009, doi: 10.1002/adfm.200801824.

[42] H. R. Williams, R. S. Trask, and I. P. Bond, "Self-healing composite sandwich structures," Smart Mater. Struct., 2007, doi: 10.1088/0964-1726/16/4/031.

[43] H. R. Williams, R. S. Trask, and I. P. Bond, "Self-healing sandwich panels: Restoration of compressive strength after impact," Compos. Sci. Technol., 2008, doi: 10.1016/j.compscitech.2008.07.016.

[44] A. M. Coppola, P. R. Thakre, N. R. Sottos, and S. R. White, "Tensile properties and damage evolution in vascular 3D woven glass/epoxy composites," Compos. Part A Appl.Sci. Manuf., 2014, doi: 10.1016/j.compositesa.2013.12.006.

[45] C. J. Norris, G. J. Meadway, M. J. O’Sullivan, I. P. Bond, and R. S. Trask, "Self-healing fibre reinforced composites via a bioinspired vasculature," Adv. Funct. Mater., vol. 21, no. 19, pp. 3624-3633, 2011, doi: 10.1002/adfm.201101100.

[46] A. Kousourakis, M. K. Bannister, and A. P. Mouritz, "Tensile and compressive properties of polymer laminates containing internal sensor cavities," Compos. Part A Appl. Sci. Manuf., 2008, doi: 10.1016/j.compositesa.2008.05.003.

[47] C. Y. Huang, R. S. Trask, and I. P. Bond, "Characterization and analysis of carbon fibre-reinforced polymer composite laminates with embedded circular vasculature,” J. R. Soc. Interface, vol. 7, no. 49, pp. 1229-1241, 2010, doi: 10.1098/rsif.2009.0534.

[48] A. M. Aragón, J. K. Wayer, P. H. Geubelle, D. E. Goldberg, and S. R. White, "Design of microvascular flow networks using multi-objective genetic algorithms," Comput. Methods Appl. Mech. Eng., 2008, doi: 10.1016/j.cma.2008.05.025.

[49] T. D. Prasad and N. S. Park, "Multiobjective genetic algorithms for design of water distribution networks," J. Water Resour. Plan. Manag., 2004, doi: 10.1061/(ASCE)0733-9496(2004)130:1(73).

[50] A. R. Simpson, G. C. Dandy, and L. J. Murphy, "Genetic algorithms compared to other techniques for pipe optimization," J. Water Resour. Plan. Manag., 1994, doi: 10.1061/(ASCE)07339496(1994)120:4(423).

[51] E. K. Burke and K. Graham, "Search methodologies: Introductory tutorials in optimization and decision support techniques, second edition," Search Methodol. Introd. Tutorials Optim. Decis. Support Tech. Second Ed., pp. 1-716, 2014, doi: 10.1007/978-1-4614-6940-7.

[52] K. Vairavamoorthy and M. Ali, "Optimal design of water distribution systems using genetic algorithms," 2000, doi: 10.1111/0885-9507.00201.

[53] S. V. Kumar, T. A. Dovy, J. W. Baugh, E. D. Brill, and S. R. Ranjithan, "Optimal design of redundant water distribution networks using a cluster of workstations," J. Water Resour. Plan. Manag., 2006, doi: 10.1061/(ASCE)0733-9496(2006)132:5(374).

[54] J. W. C. Pang and I. P. Bond, “'Bleeding composites' - Damage detection and self-repair using a biomimetic approach,” 2005, doi: 10.1016/j.compositesa.2004.06.016.

[55] J. W. C. Pang and I. P. Bond, "A hollow fibre reinforced polymer composite encompassing self-healing and enhanced damage visibility," Compos. Sci. Technol., 2005, doi: 10.1016/j.compscitech.2005.03.008.

[56] G. Williams, R. Trask, and I. Bond, "A self-healing carbon fibre reinforced polymer for aerospace applications," Compos. Part A Appl. Sci. Manuf., 2007, doi: 10.1016/j.compositesa.2007.01.013.

[57] V. C. Li, Y. M. Lim, and Y. W. Chan, "Feasibility study of a passive smart self-healing cementitious composite," Compos. Part B Eng., vol. 29, no. 6, pp. 819-827, 1998, doi: 10.1016/S13598368(98)00034-1.

[58] H. Huang, G. Ye, and Z. Shui, "Feasibility of self-healing in cementitious materials - By using capsules or a vascular system?," Constr. Build. Mater., 2014, doi: 10.1016/j.conbuildmat.2014.04.028.

[59] B. L. Freeman and T. Jefferson, "The simulation of transport processes in cementitious materials with 
embedded healing systems," Int. J. Numer. Anal. Methods Geomech., vol. 44, no. 2, pp. 293-326, 2020, doi: 10.1002/nag.3017.

[60] T. Selvarajoo, R. E. Davies, D. R. Gardner, B. L. Freeman, and A. D. Jefferson, "Characterisation of a vascular self-healing cementitious material system : Flow and curing properties," Constr. Build. Mater., vol. 245, p. 118332, 2020, doi: 10.1016/j.conbuildmat.2020.118332.

[61] C. Joseph, A. D. Jefferson, B. Isaacs, R. Lark, and D. Gardner, "Experimental investigation of adhesivebased self-healing of cementitious materials," Mag. Concr. Res., vol. 62, no. 11, pp. 831-843, 2010, doi 10.1680/macr.2010.62.11.831.

[62] Y. Kuang and J. Ou, "Self-repairing performance of concrete beams strengthened using superelastic SMA wires in combination with adhesives released from hollow fibers," Smart Mater. Struct., vol. 17, no. 2, 2008, doi: 10.1088/0964-1726/17/2/025020.

[63] S. Pareek, K. C. Shrestha, Y. Suzuki, T. Omori, R. Kainuma, and Y. Araki, "Feasibility of externally activated self-repairing concrete with epoxy injection network and $\mathrm{Cu}-\mathrm{Al}-\mathrm{Mn}$ superelastic alloy reinforcing bars," Smart Mater. Struct., vol. 23, no. 10, 2014, doi: 10.1088/0964-1726/23/10/105027.

[64] P. Minnebo, G. Thierens, G. De Valck, K. Van Tittelboom, N. De Belie, D. Van Hemelrijck, and E. Tsangouri, "A novel design of autonomously healed concrete: Towards a vascular healing network," Materials (Basel)., vol. 10, no. 1, pp. 1-23, 2017, doi: 10.3390/ma10010049.

[65] A. Formia, S. Terranova, P. Antonaci, N. M. Pugno, and J. M. Tulliani, "Setup of extruded cementitious hollow tubes as containing/releasing devices in self-healing systems," Materials (Basel)., vol. 8, no. 4, pp. 1897-1923, 2015, doi: 10.3390/ma8041897.

[66] R. S. Trask and I. P. Bond, "Bioinspired engineering study of Plantae vascules for self-healing composite structures," no. December 2009, pp. 921-931, 2010.

[67] C. J. Norris, G. J. Meadway, M. J. O. Sullivan, I. P. Bond, and R. S. Trask, "Self-Healing Fibre Reinforced Composites via a Bioinspired Vasculature," pp. 3624-3633,2011, doi: 10.1002/adfm.201101100.

[68] R. Davies, A. Jefferson, R. Lark, and D. Gardner, "A novel 2D vascular network in cementitious materials," Concr. - Innov. Des. fib Symp. Proc., pp. 249-250, 2015.

[69] Z. Li, L. R. de Souza, C. Litina, A. E. Markaki, and A. Al-Tabbaa, "Feasibility of Using 3D Printed Polyvinyl Alcohol," Materials (Basel)., 2019.

[70] M. I. Baker, S. P. Walsh, Z. Schwartz, and B. D. Boyan, "A review of polyvinyl alcohol and its uses in cartilage and orthopedic applications," J. Biomed. Mater. Res. - Part B Appl. Biomater., vol. 100 B, no. 5, pp. 1451-1457, 2012, doi: 10.1002/jbm.b.32694.

[71] D. Therriault, S. R. White, and J. A. Lewis, "Chaotic mixing in three-dimensional microvascular networks fabricated by direct-write assembly," Nat. Mater., 2003, doi: 10.1038/nmat863.

[72] N. W. Choi, M. Cabodi, B. Held, J. P. Gleghorn, L. J. Bonassar, and A. D. Stroock, "Microfluidic scaffolds for tissue engineering," Nat. Mater., 2007, doi: 10.1038/nmat2022.

[73] A. P. Golden and J. Tien, "Fabrication of microfluidic hydrogels using molded gelatin as a sacrificial element," Lab Chip, 2007, doi: 10.1039/b618409j.

[74] L. L. Bellan, T. Kniazeva, E. E. Kim, A. A. Epshteyn, D. D. Cropek, R. Langer, and J. J. Borenstein, "Fabrication of a hybrid microfluidic system incorporating both lithographically patterned microchannels and a 3D fiber-formed microfluidic network," Adv. Healthc. Mater., 2012, doi: 10.1002/adhm.201100052.

[75] J. He, M. Mao, Y. Liu, J. Shao, Z. Jin, and D. Li, "Fabrication of nature-inspired microfluidic network for perfusable tissue constructs," Adv. Healthc. Mater., 2013, doi: 10.1002/adhm.201200404.

[76] B. D. Therriault, R. F. Shepherd, S. R. White, and J. A. Lewis, "Fugitive Inks for Direct-Write Assembly of Three-Dimensional Microvascular Networks **," no. 4, pp. 395-399, 2005, doi: 10.1002/adma.200400481.

[77] W. Wu, C. J.Hansen, A. M. Aragón, P. H. Geubelle, S. R. White, and J. A. Lewis, "Direct-write assembly of biomimetic microvascular networks for efficient fluid transport," Soft Matter, vol. 6, no. 4, pp. 739-742, 2010, doi: 10.1039/b918436h.

[78] I. (Sigma-A. C. Koltover, "Novel Inks for Direct-Write Assembly of 3D Periodic Structures," Mater. Matters, 2008, doi: 1933-9631.

[79] C. J. Hansen, S. R. White, N. R. Sottos, and J. A. Lewis, “Accelerated self-healing via ternary interpenetrating microvascular networks,” Adv. Funct. Mater., 2011, doi: 10.1002/adfm.201101553.

[80] A. P. Esser-Kahn, P. R. Thakre, H. Dong, J. F. Patrick, V. K. Vlasko-Vlasov, N. R. Sottos, J. S. Moore, and S. R. White, "Three-dimensional microvascular fiber-reinforced composites," Adv. Mater., 2011, doi: 10.1002/adma.201100933.

[81] J. F. Patrick, K. R. Hart, B. P. Krull, C. E. Diesendruck, J. S. Moore, S. R. White, and N. R. Sottos, 
[82] H. Dong, A. P. Esser-Kahn, P. R. Thakre, J. F. Patrick, N. R. Sottos, S. R. White, and J. S. Moore, "Chemical treatment of poly(lactic acid) fibers to enhance the rate of thermal depolymerization," ACS Applied Materials and Interfaces. 2012, doi: 10.1021/am2010042.

[83] R. C. R. Gergely, S. J. Pety, B. P. Krull, J. F. Patrick, T. Q. Doan, A. M. Coppola, P. R. Thakre, N. R. Sottos, J. S. Moore, and S. R. White, "Multidimensional vascularized polymers using degradable sacrificial templates," Adv. Funct. Mater., 2015, doi: 10.1002/adfm.201403670.

[84] H. Saghafi, A. Zucchelli, R. Palazzetti, and G. Minak, "The effect of interleaved composite nanofibrous mats on delamination behavior of polymeric composite materials," Compos. Struct., 2014, doi: 10.1016/j.compstruct.2013.10.039.

[85] D. Li and Y. Xia, "Electrospinning of nanofibers: Reinventing the wheel?," Advanced Materials. 2004," doi: 10.1002/adma.200400719.

[86] A. L. Yarin, B. Pourdeyhimi, and S. Ramakrishna, Fundamentals and applications of micro and nanofibers. 2013.

[87] X. F. Wu, A. Rahman, Z. Zhou, D. D. Pelot, S. Sinha-Ray, B. Chen, S. Payne, and A. L. Yarin, "Electrospinning core-shell nanofibers for interfacial toughening and self-healing of carbon-fiber/epoxy composites," J. Appl. Polym. Sci., 2013, doi: 10.1002/app.38838.

[88] M. W. Lee, S. An, H. S. Jo, S. S. Yoon, and A. L. Yarin, "Self-Healing Nanofiber-Reinforced Polymer Composites. 1. Tensile Testing and Recovery of Mechanical Properties," ACS Appl. Mater. Interfaces, 2015, doi: 10.1021/acsami.5b05998.

[89] M. W. Lee, S. An, H. S. Jo, S. S. Yoon, and A. L. Yarin, "Self-healing Nanofiber-Reinforced Polymer Composites. 2. Delamination/Debonding and Adhesive and Cohesive Properties," ACS Appl. Mater. Interfaces, 2015, doi: 10.1021/acsami.5b03470.

[90] S. An, M. Liou, K. Y. Song, H. S. Jo, M. W. Lee, S. S. Al-Deyab, A. L. Yarin, and S. S. Yoon, "Highly flexible transparent self-healing composite based on electrospun core-shell nanofibers produced by coaxial electrospinning for anti-corrosion and electrical insulation," Nanoscale, 2015, doi: $10.1039 / \mathrm{c} 5 \mathrm{nr} 04551 \mathrm{~g}$.

[91] T. Q. Doan, L. S. Leslie, S. Y. Kim, R. Bhargava, S. R. White, and N. R. Sottos, "Characterization of core-shell microstructure and self-healing performance of electrospun fiber coatings," Polymer (Guildf)., 2016, doi: 10.1016/j.polymer.2016.10.062.

[92] A. Greiner and J. H. Wendorff, "Electrospinning: A fascinating method for the preparation of ultrathin fibers," Angewandte Chemie - International Edition. 2007, doi: 10.1002/anie.200604646.

[93] M. J. Laudenslager, R. H. Scheffler, and W. M. Sigmund, "Electrospun materials for energy harvesting, conversion, and storage: A review," 2010, doi: 10.1351/PAC-CON-09-11-49.

[94] S. Sinha-Ray, D. D. Pelot, Z. P. Zhou, A. Rahman, X. F. Wu, and A. L. Yarin, "Encapsulation of selfhealing materials by coelectrospinning, emulsion electrospinning, solution blowing and intercalation," $J$. Mater. Chem., 2012, doi: 10.1039/c2jm15696b.

[95] L. Tsetseris and S. T. Pantelides, “Adatom complexes and self-healing mechanisms on graphene and single-wall carbon nanotubes," Carbon N. Y., 2009, doi: 10.1016/j.carbon.2008.12.002.

[96] G. Lanzara, Y. Yoon, H. Liu, S. Peng, and W. I. Lee, "Carbon nanotube reservoirs for self-healing materials," Nanotechnology, 2009, doi: 10.1088/0957-4484/20/33/335704.

[97] A. V. Bazilevsky, A. L. Yarin, and C. M. Megaridis, "Co-electrospinning of core-shell fibers using a single-nozzle technique," Langmuir, 2007, doi: 10.1021/la063194q.

[98] M. W. Lee, S. An, C. Lee, M. Liou, A. L. Yarin, and S. S. Yoon, "Self-healing transparent core-shell nanofiber coatings for anti-corrosive protection," J. Mater. Chem. A, 2014, doi: 10.1039/c4ta00623b.

[99] S. Sinha-Ray, A. L. Yarin, and B. Pourdeyhimi, "The production of 100/400 nm inner/outer diameter carbon tubes by solution blowing and carbonization of core-shell nanofibers," Carbon N. Y., 2010, doi: 10.1016/j.carbon.2010.05.056.

[100] L. Shi, X. Zhuang, X. Tao, B. Cheng, and W. Kang, "Solution blowing nylon 6 nanofiber mats for air filtration," Fibers Polym., 2013, doi: 10.1007/s12221-013-1485-5.

[101] M. W. Lee, S. S. Yoon, and A. L. Yarin, "Solution-Blown Core-Shell Self-Healing Nano- and Microfibers," ACS Appl. Mater. Interfaces, 2016, doi: 10.1021/acsami.5b12358.

[102] J. F. Su, S. Han, X. L. Zhang, and Y. Y. Wang, "Self-healing bitumen using biomimetic capillaries hollow fibers: Fabrication, microstructure and properties," 2017.

[103] J. F. Su, X. L. Zhang, Y. D. Guo, X. F. Wang, F. L. Li, Y. Fang, Z. Ding, and N. X. Han, "Experimental observation of the vascular self-healing hollow fibers containing rejuvenator states in bitumen," Constr. Build. Mater., 2019, doi: 10.1016/j.conbuildmat.2019.01.001. 
[104] X. L. Zhang, J. F. Su, Y. D. Guo, X. Y. Wang, Y. Fang, Z. Ding, and N. X. Han, "Novel vascular selfnourishing and self-healing hollow fibers containing oily rejuvenator for bitumen," Constr. Build. Mater., 2018, doi: 10.1016/j.conbuildmat.2018.06.181.

[105] J.-F. Su, "Self-healing biomimetic microvascular containing oily rejuvenator for prolonging life of bitumen," in Eco-Efficient Pavement Construction Materials, 2020.

[106] C. Dry and W. McMillan, "Three-part methylmethacrylate adhesive system as an internal delivery system for smart responsive concrete," Smart Mater. Struct., 1996, doi: 10.1088/0964-1726/5/3/007.

[107] T. Selvarajoo, R. E. Davies, B. Freeman, and A. Jefferson, "Mechanical Response of a Vascular SelfHealing Cementitious Material System Under Varying Loading Conditions.” 2020.

[108] S. Sinha-Ray, S. Khansari, A. L. Yarin, and B. Pourdeyhimi, "Effect of chemical and physical crosslinking on tensile characteristics of solution-blown soy protein nanofiber mats," Ind. Eng. Chem. Res., 2012, doi: 10.1021/ie302359x.

[109] I. Campbell, D. Bourell, and I. Gibson, "Additive manufacturing: rapid prototyping comes of age," Rapid Prototyp. J., 2012, doi: 10.1108/13552541211231563.

[110] W. Meyer, S. Engelhardt, E. Novosel, B. Elling, M. Wegener, and H. Krüger, "Soft Polymers for Building up Small and Smallest Blood Supplying Systems by Stereolithography," J. Funct. Biomater., 2012, doi: 10.3390/jfb3020257.

[111] K. Arcaute, B. K. Mann, and R. B. Wicker, "Stereolithography of three-dimensional bioactive poly(ethylene glycol) constructs with encapsulated cells," Ann. Biomed. Eng., 2006, doi: 10.1007/s10439-006-9156-y.

[112] J. Visser, B. Peters, T. J. Burger, J. Boomstra, W. J. A. Dhert, F. P. W. Melchels, and J. Malda, "Biofabrication of multi-material anatomically shaped tissue constructs," Biofabrication, 2013, doi: 10.1088/1758-5082/5/3/035007.

[113] X. Wang, M. Jiang, Z. Zhou, J. Gou, and D. Hui, “3D printing of polymer matrix composites: A review and prospective," Composites Part B: Engineering. 2017, doi: 10.1016/j.compositesb.2016.11.034.

[114] J. R. C. Dizon, A. H. Espera, Q. Chen, and R. C. Advincula, "Mechanical characterization of 3D-printed polymers," Additive Manufacturing. 2018, doi: 10.1016/j.addma.2017.12.002.

[115] F. E. Wiria, C. K. Chua, K. F. Leong, Z. Y. Quah, M. Chandrasekaran, and M. W. Lee, "Improved biocomposite development of poly(vinyl alcohol) and hydroxyapatite for tissue engineering scaffold fabrication using selective laser sintering," J. Mater. Sci. Mater. Med., 2008, doi: 10.1007/s10856-0073176-5

[116] S. Eshraghi and S. Das, "Mechanical and microstructural properties of polycaprolactone scaffolds with one-dimensional, two-dimensional, and three-dimensional orthogonally oriented porous architectures produced by selective laser sintering," Acta Biomater., 2010, doi: 10.1016/j.actbio.2010.02.002.

[117] J. M. Williams, A. Adewunmi, R. M. Schek, C. L. Flanagan, P. H. Krebsbach, S. E. Feinberg, S. J. Hollister, and S. Das, "Bone tissue engineering using polycaprolactone scaffolds fabricated via selective laser sintering," Biomaterials, 2005, doi: 10.1016/j.biomaterials.2004.11.057.

[118] M. Simonelli, Y. Y. Tse, and C. Tuck, "Effect of the build orientation on the mechanical properties and fracture modes of SLM Ti-6Al-4V," Mater. Sci. Eng. A, 2014, doi: 10.1016/j.msea.2014.07.086.

[119] ASTM F2792-12, "Standard Terminology for Additive Manufacturing Technologies," ASTM International. 2012.

[120] ISO, "ISO 17296-3:2014 Additive manufacturing - General principles - Part 3: Main characteristics and corresponding test methods," ISO 17296-32014, 2014.

[121] ISO, “Additive manufacturing - General principles - Part 2: Overview of process categories and feedstock," Iso 17296-2:2015 (E). 2015.

[122] ISO, "Specification for additive manufacturing file format (AMF) Version 1.2," Bs En Iso/Astm $529152017,2017$.

[123] ASTM 52921, "Standard Terminology for Additive Manufacturing — Coordinate Systems and Test Methodologies," ASTM Int., 2013.

[124] America Makes \& Ansi Additive Manufacturing Standardization Collaborative (Amsc), “America Makes \& Ansi Overview."

https://www.ansi.org/standards_activities/standards_boards_panels/amsc/America-Makes-and-ANSIAMSC-Overview.

[125] Edwarrd M. Petrie, Handbook of Adhesives and Sealants. 2013.

[126] S. M. Bleay, C. B. Loader, V. J. Hawyes, L. Humberstone, and P. T. Curtis, "A smart repair system for polymer matrix composites," Compos. Part A Appl. Sci. Manuf., 2001, doi: 10.1016/S1359$835 \mathrm{X}(01) 00020-3$.

[127] S. K. Tomlinson, O. R. Ghita, R. M. Hooper, and K. E. Evans, "The use of near-infrared spectroscopy 
for the cure monitoring of an ethyl cyanoacrylate adhesive," Vib. Spectrosc., vol. 40, no. 1, pp. 133-141, 2006, doi: 10.1016/j.vibspec.2005.07.009.

[128] R. C. R. Gergely, M. N. Rossol, S. Tsubaki, J. Wang, N. R. Sottos, and S. R. White, “A Microvascular System for the Autonomous Regeneration of Large Scale Damage in Polymeric Coatings," Adv. Eng. Mater., vol. 19, no. 11, pp. 1-10, 2017, doi: 10.1002/adem.201700319.

[129] K. Davami, M. Mohsenizadeh, M. Mitcham, P. Damasus, Q. Williams, and M. Munther, “Additively Manufactured Self-Healing Structures with Embedded Healing Agent Reservoirs," Sci. Rep., 2019, doi: 10.1038/s41598-019-43883-3

[130] Y. K. Song, Y. H. Jo, Y. J. Lim, S. Y. Cho, H. C. Yu, B. C. Ryu, S. I. Lee, and C. M. Chung, "Sunlightinduced self-healing of a microcapsule-type protective coating," ACS Appl. Mater. Interfaces, 2013, doi $10.1021 / \mathrm{am} 302728 \mathrm{~m}$.

[131] A. Kanelopoulos, T. S. Qureshi, and A. Al-Tabbaa, "Glass encapsulated minerals for self-healing in cement based composites," Constr. Build. Mater., pp. 1-32, 2015.

[132] R. Alghamri, A. Kanellopoulos, and A. Al-Tabbaa, "Impregnation and encapsulation of lightweight aggregates for self-healing concrete," Constr. Build. Mater., vol. 124, pp. 910-921, 2016, doi: 10.1016/j.conbuildmat.2016.07.143.

[133] A. Formia, S. Irico, F. Bertola, F. Canonico, P. Antonaci, N. M. Pugno, and J. M. Tulliani, "Experimental analysis of self-healing cement-based materials incorporating extruded cementitious hollow tubes,” J. Intell. Mater. Syst. Struct., vol. 27, no. 19, pp. 2633-2652, 2016, doi: $10.1177 / 1045389 \times 16635847$.

[134] H. M. Jonkers, A. Thijssen, G. Muyzer, O. Copuroglu, and E. Schlangen, "Application of bacteria as self-healing agent for the development of sustainable concrete," Ecol. Eng., vol. 36, no. 2, pp. 230-235, 2010, doi: 10.1016/j.ecoleng.2008.12.036.

[135] K. Van Tittelboom, N. De Belie, W. De Muynck, and W. Verstraete, "Use of bacteria to repair cracks in concrete," Cem. Concr. Res., vol. 40, no. 1, pp. 157-166, 2010, doi: 10.1016/j.cemconres.2009.08.025.

[136] K. S. Toohey, N. R. Sottos, and S. R. White, "Characterization of microvascular-based self-healing coatings," Exp. Mech., 2009, doi: 10.1007/s11340-008-9176-7.

[137] E. N. Brown, S. R. White, and N. R. Sottos, "Microcapsule induced toughening in a self-healing polymer composite,” J. Mater. Sci., 2004, doi: 10.1023/B:JMSC.0000016173.73733.dc.

[138] T. C. Mauldin, J. D. Rule, N. R. Sottos, S. R. White, and J. S. Moore, "Self-healing kinetics and the stereoisomers of dicyclopentadiene," J. R. Soc. Interface, 2007, doi: 10.1098/rsif.2006.0200.

[139] M. W. Lee, S. Sett, S. S. Yoon, and A. L. Yarin, "Fatigue of Self-Healing Nanofiber-based Composites: Static Test and Subcritical Crack Propagation," ACS Appl. Mater. Interfaces, 2016, doi: 10.1021/acsami.6b05390.

[140] M. W. Lee, S. Sett, S. S. Yoon, and A. L. Yarin, "Self-healing of nanofiber-based composites in the course of stretching," Polymer (Guildf)., 2016, doi: 10.1016/j.polymer.2016.09.037.

[141] S. Flint, T. Markle, S. Thompson, and E. Wallace, "Bisphenol A exposure, effects, and policy: A wildlife perspective," Journal of Environmental Management. 2012, doi: 10.1016/j.jenvman.2012.03.021.

[142] K. Van Tittelboom, K. Adesanya, P. Dubruel, P. Van Puyvelde, and N. De Belie, "Methyl methacrylate as a healing agent for self-healing cementitious materials," Smart Mater. Struct., vol. 20, no. 12, 2011, doi: 10.1088/0964-1726/20/12/125016.

[143] T. Bhattacharjee, S. M. Zehnder, K. G. Rowe, S. Jain, R. M. Nixon, W. G. Sawyer, and T. E. Angelini, "Writing in the granular gel medium," Sci. Adv., 2015, doi: 10.1126/sciadv.1500655.

[144] S. R. White, J. S. Moore, N. R. Sottos, B. P. Krull, W. A. Santa Cruz, and R. C. R. Gergely, "Restoration of large damage volumes in polymers," Science (80-. )., 2014, doi: 10.1126/science.1251135.

[145] J. Wang, K. Van Tittelboom, N. De Belie, and W. Verstraete, "Use of silica gel or polyurethane immobilized bacteria for self-healing concrete," Constr. Build. Mater., vol. 26, no. 1, pp. 532-540, 2012, doi: 10.1016/j.conbuildmat.2011.06.054.

[146] D. Gardner, A. Jefferson, A. Hoffman, and R. Lark, "Simulation of the capillary flow of an autonomic healing agent in discrete cracks in cementitious materials," Cem. Concr. Res., vol. 58, pp. 35-44, 2014, doi: 10.1016/j.cemconres.2014.01.005.

[147] K. S. Toohey, N. R. Sottos, J. A. Lewis, J. S. Moore, and S. R. White, "Self-healing materials with microvascular networks," Nat. Mater., 2007, doi: 10.1038/nmat1934.

[148] K. Van Tittelboom and N. De Belie, Self-healing in cementitious materials-a review, vol. 6, no. 6. 2013.

[149] K. Van Tittelboom, E. Tsangouri, D. Van Hemelrijck, and N. De Belie, "The efficiency of self-healing concrete using alternative manufacturing procedures and more realistic crack patterns," Cem. Concr. Compos., 2015, doi: 10.1016/j.cemconcomp.2014.12.002.

[150] J. Wang, K. Van Tittelboom, N. De Belie, and W. Verstraete, "Use of silica gel or polyurethane 
immobilized bacteria for self-healing concrete," Constr. Build. Mater., 2012, doi: 10.1016/j.conbuildmat.2011.06.054.

[151] E. Mostavi, S. Asadi, M. M. Hassan, and M. Alansari, "Evaluation of self-healing mechanisms in concrete with double-walled sodium silicate microcapsules," J. Mater. Civ. Eng., vol. 27, no. 12, pp. 18, 2015, doi: 10.1061/(ASCE)MT.1943-5533.0001314.

[152] M. W. Keller, S. R. White, and N. R. Sottos, "A self-healing poly(dimethyl siloxane) elastomer," $A d v$. Funct. Mater., 2007, doi: 10.1002/adfm.200700086.

[153] I. P. S. Qamar, “Development of 3D Printed Vascular Networks for Repeated Self-Healing,” University of Bristol, 2017.

[154] A. Kousourakis, A. P. Mouritz, and M. K. Bannister, "Interlaminar properties of polymer laminates containing internal sensor cavities," Compos. Struct., 2006, doi: 10.1016/j.compstruct.2006.04.086.

[155] C. J. Norris, J. A. P. White, G. McCombe, P. Chatterjee, I. P. Bond, and R. S. Trask, “Autonomous stimulus triggered self-healing in smart structural composites," Smart Mater. Struct., 2012, doi: 10.1088/0964-1726/21/9/094027.

[156] R. S. Trask, C. J. Norris, and I. P. Bond, "Stimuli-triggered self-healing functionality in advanced fibrereinforced composites,” J. Intell. Mater. Syst. Struct., 2014, doi: 10.1177/1045389X13505006.

[157] T. Nishiwaki, H. Mihashi, B. K. Jang, and K. Miura, "Development of self-healing system for concrete with selective heating around crack," J. Adv. Concr. Technol., vol. 4, no. 2, pp. 267-275, 2006, doi: 10.3151/jact.4.267.

[158] A. R. Hamilton, N. R. Sottos, and S. R. White, "Pressurized vascular systems for self-healing materials," J. R. Soc. Interface, pp. 1020-1028, 2011.

[159] K. Van Tittelboom, N. De Belie, D. Van Loo, and P. Jacobs, "Self-healing efficiency of cementitious materials containing tubular capsules filled with healing agent," Cem. Concr. Compos., vol. 33, no. 4, pp. 497-505, 2011, doi: 10.1016/j.cemconcomp.2011.01.004.

[160] J. Feiteira, E. Tsangouri, E. Gruyaert, C. Lors, G. Louis, and N. De Belie, "Monitoring crack movement in polymer-based self-healing concrete through digital image correlation," Mater. Des., vol. 115, pp. 238-246, 2017, doi: 10.1016/j.matdes.2016.11.050.

[161] P. Minnebo, G. Thierens, G. De Valck, K. Van Tittelboom, and N. De Belie, "A Novel Design of Autonomously Healed Concrete :," Materials (Basel)., pp. 1-23, 2017, doi: 10.3390/ma10010049.

[162] G. D. Stafford and R. W. Handley, "Transverse bend testing of denture base polymers," J. Dent., 1975, doi: 10.1016/0300-5712(75)90030-5.

[163] K. T. Wan and Y. W. Mai, "Fracture mechanics of a shaft-loaded blister of thin flexible membrane on rigid substrate," Int. J. Fract., 1995, doi: 10.1007/BF00036264.

[164] H. Na, P. Chen, K. T. Wan, S. C. Wong, Q. Li, and Z. Ma, "Measurement of adhesion work of electrospun polymer membrane by shaft-loaded blister test," Langmuir, 2012, doi: 10.1021/la300877r.

[165] W. Li, Z. Jiang, and Z. Yang, "Acoustic characterization of damage and healing of microencapsulationbased self-healing cement matrices," Cem. Concr. Compos., vol. 84, pp. 48-61, 2017, doi: 10.1016/j.cemconcomp.2017.08.013.

[166] K. Van Tittelboom, J. Wang, M. Araújo, D. Snoeck, E. Gruyaert, B. Debbaut, H. Derluyn, V. Cnudde, E. Tsangouri, D. Van Hemelrijck, and N. De Belie, "Comparison of different approaches for self-healing concrete in a large-scale lab test," Constr. Build. Mater., vol. 107, pp. 125-137, 2016, doi: 10.1016/j.conbuildmat.2015.12.186.

[167] D. Snoeck, F. Malm, V. Cnudde, C. U. Grosse, and K. Van Tittelboom, "Validation of Self-Healing Properties of Construction Materials through Nondestructive and Minimal Invasive Testing," Advanced Materials Interfaces. 2018, doi: 10.1002/admi.201800179.

[168] Joao Feiteira, "Self-Healing Concrete Encapsulated Polymer Precursors as Healing Agents for Active Cracks," Universiteit Gent, 2017.

[169] A. Jefferson, T. Selvarajoo, B. Freeman, and R. Davies, "An experimental and numerical study on vascular self-healing cementitious materials," MATEC Web Conf., vol. 289, p. 01004, 2019, doi: 10.1051/matecconf/201928901004.

[170] J. Whitney, C. Browning, and A. Mair, "Analysis of the Flexure Test for Laminated Composite Materials," in Composite Materials: Testing and Design (Third Conference), 2009.

[171] E. I. Materials et al., "Standard Test Method for Flexural Properties of Unreinforced and Reinforced Plastics and Electrical Insulating Materials by Four-Point Bending," Annu. B. ASTM Stand., 2010, doi: 10.1520/D6272-10.1.

[172] S. Khansari, S. Sinha-Ray, A. L. Yarin, and B. Pourdeyhimi, "Stress-strain dependence for soy-protein nanofiber mats," J. Appl. Phys., 2012, doi: 10.1063/1.3682757.

[173] S. Sinha-Ray, A. L. Yarin, and B. Pourdeyhimi, "Meltblown fiber mats and their tensile strength," 
Polymer (Guildf)., 2014, doi: 10.1016/j.polymer.2014.05.025.

[174] S. Khansari, S. Sinha-Ray, A. L. Yarin, and B. Pourdeyhimi, "Biopolymer-based nanofiber mats and their mechanical characterization," Ind. Eng. Chem. Res., 2013, doi: 10.1021/ie402246x.

[175] B. M. Malyshev and R. L. Salganik, "The strength of adhesive joints using the theory of cracks," Int. J. Fract. Mech., 1965, doi: 10.1007/BF00186749.

[176] M. Maes, K. Van Tittelboom, and N. De Belie, "The efficiency of self-healing cementitious materials by means of encapsulated polyurethane in chloride containing environments," Constr. Build. Mater., vol. 71, pp. 528-537, 2014, doi: 10.1016/j.conbuildmat.2014.08.053.

[177] C. Edvardsen, "Water permeability and autogenous healing of cracks in concrete," ACI Mater. J., 1999, doi: $10.14359 / 645$.

[178] M. Rooij, K. van Tittelboom, N. Belie, and E. Schlangen, Self-Healing Phenomena in Cement-Based Materials: State-of-the-Art Report of RILEM Technical Committee. 2013.

[179] R. F. Egerton, Physical principles of electron microscopy: An introduction to TEM, SEM, and AEM. 2005.

[180] C. M. Dry, "Smart earthquake-resistant materials: using time-released adhesives for damping, stiffening, and deflection control," in 3rd International Conference on Intelligent Materials and 3rd European Conference on Smart Structures and Materials, Apr. 1996, p. 958, doi: 10.1117/12.237085.

[181] C. Dry, "In-Service Repair of Highway Bridges and Pavements by Internal Time-Release Repair Chemicals," Innov. DESERVING Explor. Anal. PROGRAMS Manag. BY Transp. Res. BOARD, 2001.

[182] C. M. Dry, "Repair and prevention of damage due to transverse shrinkage cracks in bridge decks," 1999 , doi: $10.1117 / 12.348675$.

[183] R. Davies, O. Teall, M. Pilegis, A. Kanellopoulos, T. Sharma, A. Jefferson, D. Gardner, A. Al-Tabbaa, K. Paine, and R. Lark, "Large Scale Application of Self-Healing Concrete: Design, Construction, and Testing,” Front. Mater., vol. 5, no. September, pp. 1-12, 2018, doi: 10.3389/fmats.2018.00051.

[184] E. Tsangouri, J. Lelon, P. Minnebo, H. Asaue, T. Shiotani, K. Van Tittelboom, N. De Belie, D. G. Aggelis, and D. Van Hemelrijck, "Feasibility study on real-scale, self-healing concrete slab by developing a smart capsules network and assessed by a plethora of advanced monitoring techniques," Constr. Build. Mater., vol. 228, p. 116780, 2019, doi: 10.1016/j.conbuildmat.2019.116780.

[185] K. van Breugel, "Is there a market for self-healing cement-based materials?," 1st international conference on self-healing materials. 2007.

[186] P. Van den Heede, A. Mignon, G. Habert, and N. De Belie, "Cradle-to-gate life cycle assessment of selfhealing engineered cementitious composite with in-house developed (semi-)synthetic superabsorbent polymers," Cem. Concr. Compos., 2018, doi: 10.1016/j.cemconcomp.2018.08.017.

[187] P. Van den Heede, N. De Belie, F. Pittau, G. Habert, and A. Mignon, "Life cycle assessment of selfhealing engineered cementitious composite (SH-ECC) used for the rehabilitation of bridges," 2019.

[188] C. De Nardi, D. Gardner, and A. D. Jefferson, "Development of 3D Printed Networks in Self-Healing Concrete," Materials (Basel)., 2020, doi: 10.3390/ma13061328.

[189] A. Al-Shawk, H. Tanabi, and B. Sabuncuoglu, "Investigation of stress distributions in the resin rich region and failure behavior in glass fiber composites with microvascular channels under tensile loading," Compos. Struct., 2018, doi: 10.1016/j.compstruct.2018.02.061. 